
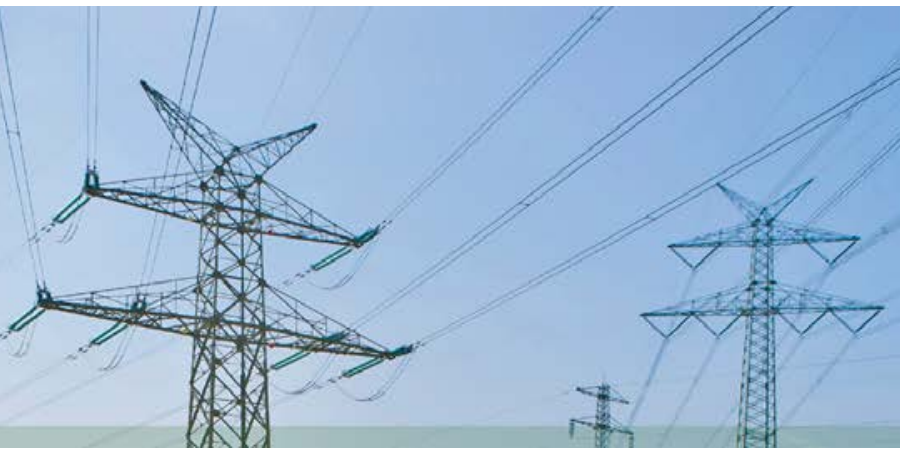

\title{
Mexico's Regulatory Engagement in Bulk Electric Power System Planning: An Overview of U.S. Practices and Tools
}

Barbara O'Neill, David Hurlbut, Ivonne Pena,

Douglas Gagne, Jeff Cook, and Ricardo Bracho National Renewable Energy Laboratory 


\section{Mexico's Regulatory Engagement in Bulk Electric Power System Planning: An Overview of U.S. Practices and Tools}

Barbara O'Neill, David Hurlbut, Ivonne Pena, Douglas Gagne, Jeff Cook, and Ricardo Bracho National Renewable Energy Laboratory

Prepared under Task No. WFE2.5011

NREL is a national laboratory of the U.S. Department of Energy, Office of Energy Efficiency \& Renewable Energy, operated by the Alliance for Sustainable Energy, LLC.

National Renewable Energy Laboratory 15013 Denver West Parkway Golden, CO 80401

303-275-3000 • www.nrel.gov
Technical Report

NREL/TP-5D00-66103

June 2016

Contract No. DE-AC36-08GO28308 


\section{NOTICE}

This report was prepared as an account of work sponsored by an agency of the United States government. Neither the United States government nor any agency thereof, nor any of their employees, makes any warranty, express or implied, or assumes any legal liability or responsibility for the accuracy, completeness, or usefulness of any information, apparatus, product, or process disclosed, or represents that its use would not infringe privately owned rights. Reference herein to any specific commercial product, process, or service by trade name, trademark, manufacturer, or otherwise does not necessarily constitute or imply its endorsement, recommendation, or favoring by the United States government or any agency thereof. The views and opinions of authors expressed herein do not necessarily state or reflect those of the United States government or any agency thereof.

NREL prints on paper that contains recycled content 


\section{Executive Summary}

Mexico's transition to a modern wholesale power market will place new demands on how regulators evaluate and approve transmission expansion projects. Transmission projects in a modern wholesale market fulfill one of several needs, and utilities, regional transmission organizations (RTOs), and regulatory authorities in the United States have encountered comparable challenges in their market transitions to ensure projects meeting each type of need can be built. The purpose of this report is to open a window to view that experience. The report examines key practices of different U.S. jurisdictions that have moved from transmission planning to transmission approval, and it focuses on the role of the regulator in supporting a planning process that equitably meets identified needs.

This report is written primarily for the Comisión Reguladora de Energía (CRE), Centro Nacional de Control de Energía (CENACE), and Secretaría de Energía (SENER). The report's first objective is to highlight the role of regulators in different types of U.S. transmission planning processes and identify the decision-making tools they use. In the United States, the regulator's role varies geographically (e.g., by state), by market structure (i.e., a competitive market versus a vertically integrated utility), and jurisdictionally (i.e., federal roles versus state roles), but all regulators face some common challenges. The challenges include establishing an equitable openaccess transmission planning process, assessing benefits and costs for the purpose of considering project cost allocation, and establishing the bulk electric system reliability metrics and planning tools that will be used to evaluate proposed transmission projects.

A second and closely related objective is to help CRE identify the human resource skill sets it will need internally to fulfill its expected role in transmission planning. To determine which projects are consistent with the public interest, CRE will need the capability to evaluate complex technical and economic data independently of other state or private entities. Regulatory staff might rarely need to run such models themselves, but they should have sufficient background to monitor stakeholder meetings, engage in detailed discussions with those who run the models, and authoritatively interpret modeling results to the agency's ultimate decision makers.

Central planning for Mexico's bulk electric power system is documented in the Development Program of the National Electricity System (PRODESEN). The government uses PRODESEN to inform the infrastructure development needed to meet electricity demand. SENER, which is responsible for the PRODESEN process, explains the following:

The PRODESEN includes the current generation facilities and future power plants that appear on record. These indicative figures include only utility-scale projects and do not include distributed generation, but future PRODESEN reports are expected to start including expectations of distributed generation by technology. The PRODESEN also includes projects for the expansion and modernization of the national transmission and distribution networks. For the first time, the planning of the power sector is provided in a comprehensive way that includes planned projects from Comisión Federal de Electricidad (CFE) and from the private sector.

The proposed expansion and modernization of the transmission network in PRODESEN is provided by the CENACE and must be evaluated by CRE. The 
projects aim to modernize and expand the networks to solve congestion, reduce losses, and encourage the use of more efficient technologies such as high-voltage direct current (DC) transmission. The PRODESEN incorporates the growth of clean energy technologies to promote a more diversified and energy-efficient grid, thus helping to meet the goal of $25 \%$ clean generation by 2018 and $35 \%$ by 2024 (SENER 2015).

This report is organized as follows:

- Transmission expansion planning and approval in the United States

This chapter describes the regulatory role in the approval process for transmission expansion, and it highlights practices in select states. The chapter discusses regulatory staff engagement, either formally or informally, wherein transmission owners or developers propose infrastructure investment. In the United States, states differ in their protocols for whether staff or commissioners can engage in processes related to cost recovery. Examples from the Texas and California public utility commissions were chosen because these states have interties with Mexico that could become increasingly important. The process used by the Colorado Public Utilities Commission is also highlighted. Colorado is a state that has a large, vertically integrated utility and no formal independent system operator or power, somewhat like Mexico before restructuring. This chapter also describes the regulator's role in long-term strategic-planning initiatives such as competitive renewable energy zones (CREZs) in Texas.

- Cost-benefit analysis

Transmission projects that emerge from the planning processes described in the previous chapter have economic impacts that regulators need to evaluate objectively. A costbenefit analysis (CBA) is a commonly used framework for measuring economic impacts. CBAs have been applied to specific transmission projects and to strategic expansions such as CREZs. A CBA can inform regulatory decisions about how to allocate the cost of a new project, especially if some portion of project costs are to be socialized and some are to be assigned directly to specific beneficiaries. This chapter begins by describing the basic components of a CBA and the kinds of questions to which it is applied to answer. The chapter then discusses the different types of inputs required and the benefits that the methodology can examine, drawing on examples introduced in the previous sections.

- Modeling and measuring reliability in the bulk electric power system

Ensuring reliability is fundamental to all transmission planning assessments and is needed regardless of the resource mix on the electric system. However, the increased adoption of variable renewable resources has changed how RTOs and utilities consider and account for reliability, and although reliability standards themselves have not been affected, variable renewable resource generation introduces a need for additional reliability metrics and may also modify the reliability threshold criteria for some traditional metrics. Reliability can be categorized into areas of planning and operations. Transmission expansion falls into the planning side. Reserve margins can be in either area depending on whether they pertain to short-term operations or long-term planning. At the system level, some RTOs with competitive markets are reexamining how they determine operating reserve margins. On the planning side, they are also exploring 
different approaches to estimating the capacity value of wind and solar generators. These tended to be incorrectly valued when traditional metrics were applied that were based on resource uncertainty or because of the inability to perfectly forecast. The reliabilityrelated need for new transmission is impacted by metrics such as expected unserved energy, loss-of-load expectation, and other standards that are used by regulators. This chapter also describes the different types of models that are used in transmission planning. Different models answer different questions, some that arise in regulatory proceedings and some that seldom do. The chapter also explains how models are classified and applied and the information that is needed to operate them and interpret results.

- Case study on interties

One specific application of the tools described in the report is in DC interties among asynchronous grids. Three such ties already exist along the Rio Grande between Mexico's grid and the Electric Reliability Council of Texas. This chapter examines the methodology used by the Public Utility Commission of Texas to examine and approve the largest of these three interties.

This report covers two types of grid modernization. One is the incremental addition of new technologies to the system, wherein the benefits that accrue are mostly local. These may include grid-level applications and non-transmission alternatives such as energy efficiency, energy storage, distributed generation, and demand response, but our focus is on transmission upgrades and new capacity. The proponent for this category of improvement is usually the utility, an independent transmission owner, or a generator. System modeling and a CBA can measure the impacts of an upgrade proposed by a stakeholder emphasizing near-term benefits and local effects. The regulator's two tasks are to determine whether the benefits of the upgrade outweigh its cost and to decide how to assign costs.

The other type of modernization is system-wide, and it is often driven by policy, not by an individual market participant. CREZs and the deployment of advanced metering infrastructure are examples. In these applications, modeling and a CBA are used to measure the system-wide benefits of system-wide modernization wherein costs are socialized. Often the decision that confronts the regulator is to determine the option that constitutes the most cost-effective path for achieving the government's policy objectives.

This report does not offer specific recommendations about Mexico's regulatory reform or practices. It is intended to serve as a knowledge base for subsequent analyses of how Mexico's regulators can prepare for their new role in a reformed electricity market. Numerous possible next steps are identified and discussed in the final chapters. 


\section{List of Acronyms}

CAISO
CBA
CCN
CENACE
CFE
CFE
CPCN
CPUC
CRE
CREZ
DC
ERCOT
FERC
kV
NERC
NPV
NREL
PRODESEN
PSCAD
PSLF
PSS/E
PUC
PUCT
ReEDS
RPM
RTO
SENER
TEAM
VOLL

California Independent System Operator cost-benefit analysis

Certificate of Convenience and Necessity

Centro Nacional de Control de Energía

Comisión Federal de Electricidad

Comisión Federal de Electricidad

Certificate of Public Convenience and Necessity

California Public Utilities Commission

Comisión Reguladora de Energía

competitive renewable energy zone

direct current

Electric Reliability Council of Texas

Federal Energy Regulatory Commission

kilovolt

North American Electric Reliability Corporation net present value

National Renewable Energy Laboratory

Development Program of the National Electricity

System

Power System Computer Aided Design

Positive Sequence Load Flow

Power System Simulation for Engineers

Public Utilities Commission (of Colorado)

Public Utility Commission of Texas

Regional Energy Deployment System

Resource Planning Model

regional transmission organization

Secretaría de Energía

Transmission Economic Assessment Methodology value of lost load 


\section{Table of Contents}

1 Transmission Expansion Planning and Approval in the United States .................................... 1

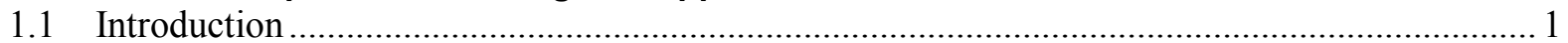

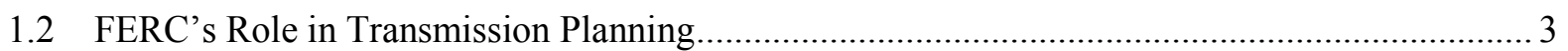

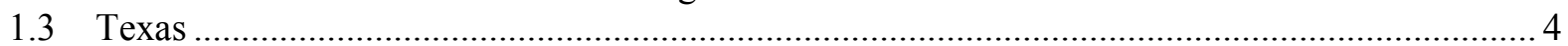

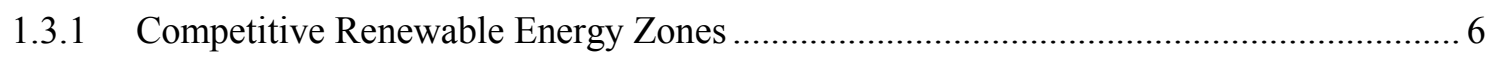

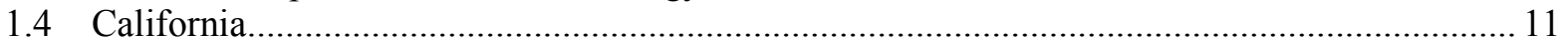

1.4.1 California Public Utilities Commission's Certificate of Convenience and Necessity

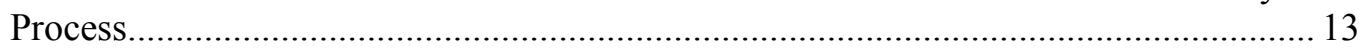

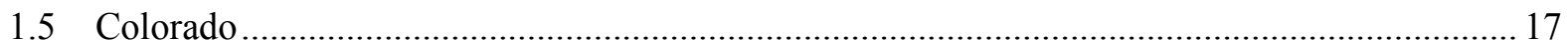

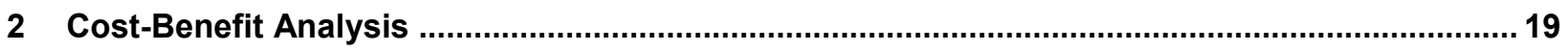

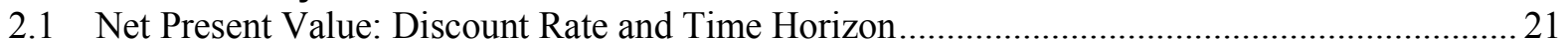

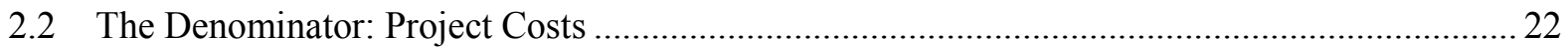

2.3 The Numerator: Attributable Benefits.................................................................................. 23

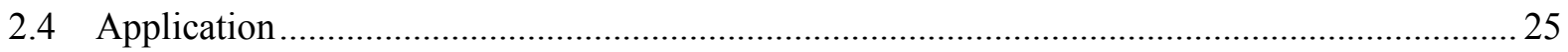

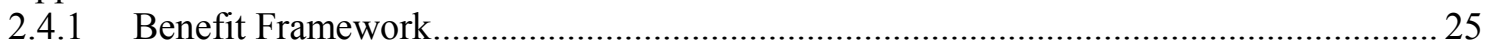

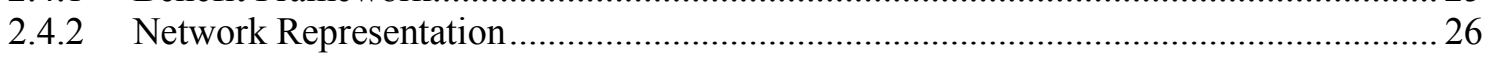

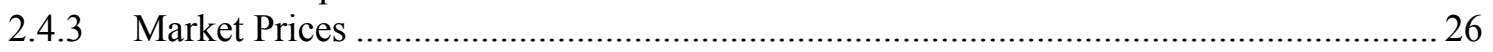

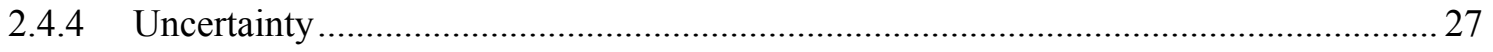

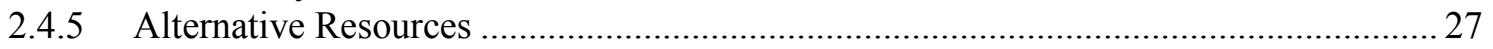

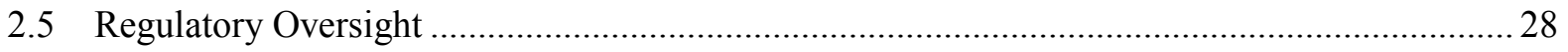

3 Modeling and Measuring Reliability in the Bulk Electric Power System .....................................29

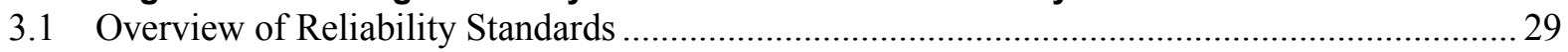

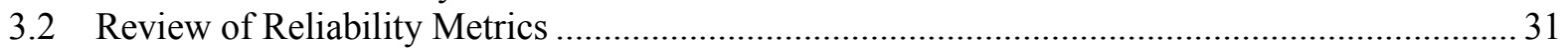

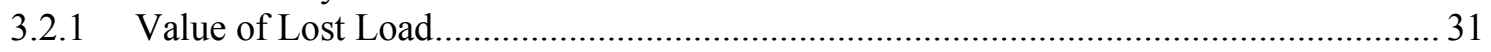

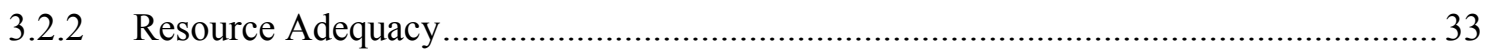

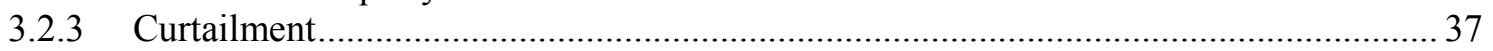

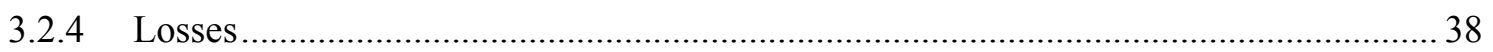

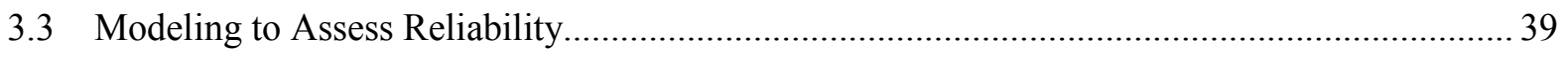

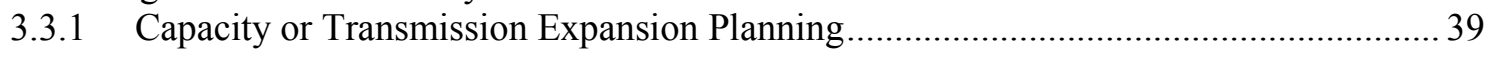

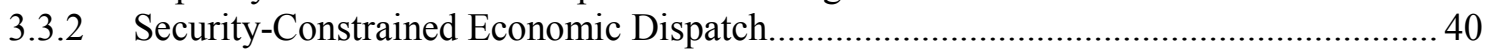

3.3.3 Power Flow and Contingency Planning ........................................................... 42

4 Case Study: Regulatory Evaluation of Direct Current Intertie between Mexico and the Electric

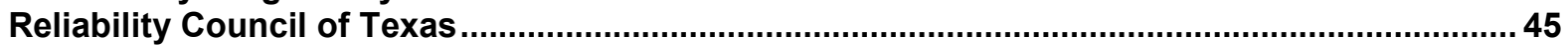

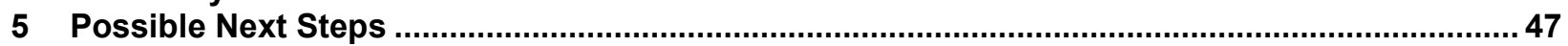

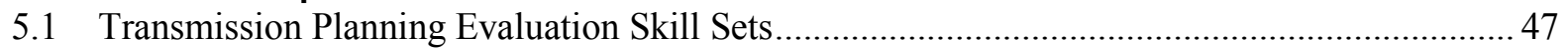

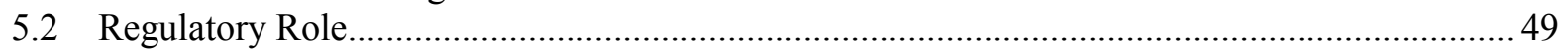

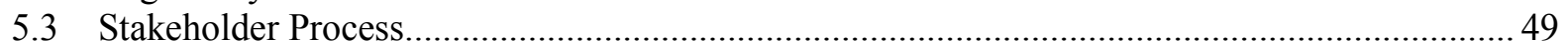

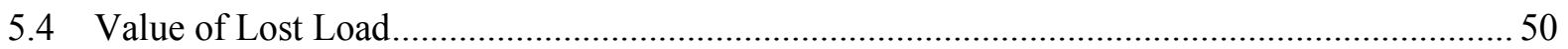

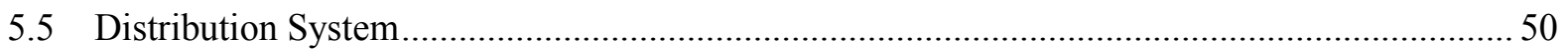

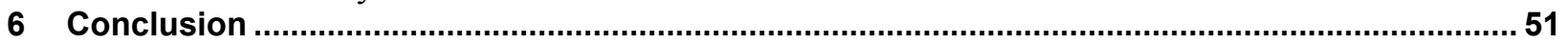

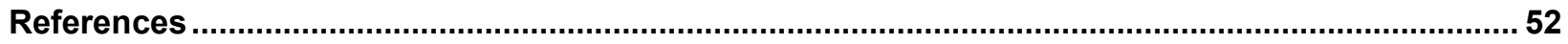




\section{List of Figures}

Figure 1. Wind CREZs in ERCOT with $345-\mathrm{kV}$ lines connecting wind to network load. Image from ERCOT (2008)

Figure 2. CREZs in the western United States with proposed 500-kV DC line connecting Wyoming wind to load in California. Image from Western Governors' Association and U.S. Department of

Energy (2009)

Figure 3. CPUC process for a new transmission line permit. Image from (CPUC 2009) ........................ 16

Figure 4. Historic permitting timeline at CPUC. Project time is taken from application deemed complete to a commission decision. Image from Transmission and Environmental Permitting Team of CPUC (2009)

Figure 5. Optimal replacement age. Image from Winsor and Buncombe (2007).................................. 19

Figure 6. Effect of discount rate on value of future benefits .............................................................. 21

Figure 7. Sensitivity analysis of future renewable energy costs and avoided transmission. Image from

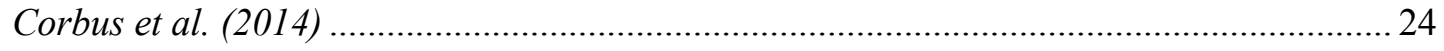

Figure 8. Comparison of VOLL among sectors and countries. Image from Welle and Zwaan (2007) ...... 33

Figure 9. Load that can be served before and after new wind. Image from Milligan (2011)..................... 34

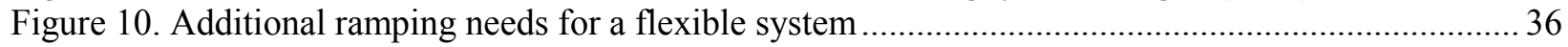

Figure 11. NREL's in-house and commercial power system modeling tools....................................... 40

\section{List of Tables}

Table 1. Categories of Potential Benefits from Transmission Expansion................................................2 22

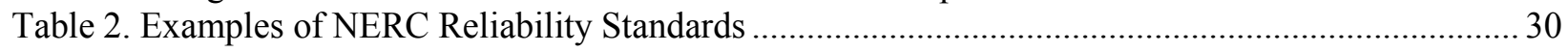

Table 3. Sample of Power System Models in use in North America........................................................ 44

Table 4. Recommended Transmission Planning Evaluation Skill Sets .................................................... 48 


\section{Transmission Expansion Planning and Approval in the United States}

\subsection{Introduction}

Any power system needs transmission investment, especially as demand for power and generation investment grows, supply portfolios shift and diversify, and aging infrastructure causes concern about safety and reliability. New transmission (or upgrades to existing transmission) may be needed to ensure reliability, reduce system costs by alleviating congestion, enhance wholesale competition, or enable access to new generation facilities that are lower in cost or that meet public policy objectives such as renewable energy goals. Sometimes new transmission will be sponsored by a specific transmission customer for a specific need. And in some cases, private, non-utility entities might seek to build their own merchant transmission to take advantage of commercial opportunities not being addressed by utility providers (National Association of Clean Air Agencies 2015).

In the case of economic upgrades, a typical goal is to lower the total system cost by building new or expanding existing transmission capacity to reach lower cost generation resources or alleviate existing transmission congestion. In the case of reliability, there are numerous technical reasons why upgrades and investments are needed. Grids evolve as load and generation shifts, and the two main barometers of a grid's health — voltage and frequency stability — can be influenced by the addition of equipment such as capacitors, series compensators, and even substations and transformers that add redundant transmission paths and "strengthen" the grid. In the case of public policy, transmission investments may be needed to aid the increase of integrating renewable generation plants that are frequently located distantly from load centers. Increased distributed generation such as rooftop photovoltaic may also be an indirect reason for transmission system investments because in aggregate, extensive distributed generation will shift the needs of the grid.

Just as there are many types of power system business models in the United States (investorowned utilities, municipals, cooperatives, rural electric utilities, federal agencies, etc.), there are many different ways that state regulatory authorities approve monopolies' asset investments to be recovered from captive ratepayers. Further, these entities have various processes for formulating a transmission plan that becomes the basis for asserting the need for investment. See page 18-3 of (National Association of Clean Air Agencies 2015). In parallel to U.S. state commissions' jurisdictions, there is the Federal Energy Regulatory Commission (FERC), which oversees interstate movement of power (both purchases/sales and transport), among other commodities. Further, U.S. utilities belong to the North American Electric Reliability Corporation (NERC). In Mexico, we do not anticipate parallel regulatory authorities such as the state and federal commissions that exist in the United States. Ultimately, the Comision Reguladora de Energía (CRE) may take on roles that include responsibilities covered by those of FERC, NERC, and state utility commissions in the United States. Although we provide state regulatory examples that we expect to help CRE in its evaluation of the Development Program of the National Electricity System (PRODESEN), FERC Orders 890 and 100 have guided recent transmission processes in the United States and should not be understated. 
For many processes that involve approving an expenditure above a threshold amount or exercising eminent domain, there is a stakeholder process that informs the development of the request. In other words, by the time a transmission expansion plan has reached a state regulatory agency such as a public utility commission, would-be interveners and affected parties have been involved along the way to shape, critique, opine, and influence the final request. In other cases, the stakeholder process happens during the actual regulatory process by the public utility authority. Although the process varies by region, in some cases it is coordinated by the independent system operator - for example, the California Independent System Operator (CAISO), Electric Reliability Council of Texas (ERCOT), and Southwest Power Pool. In Colorado, which has no independent system operator or regional transmission organization (RTO), the process is spearheaded by the Colorado Coordinated Planning Group, an organization of transmission staff from regional utilities, with active engagement from other stakeholders such as environmental coalitions, transmission and generation developers, and consumer advocacy groups.

In principle, the length and complexity of the process varies by the significance of the transmission project - e.g., cost, miles, voltage, or numbers of lines. In many cases, multiyear stakeholder processes and meeting schedules are laid out to accommodate numerous parties in disparate geographic locations. Although there is no definitive requirement for unanimous decisions, the effectiveness of stakeholder engagement can be ascertained through lessening objections and interventions as compromises are reached or justifications are accepted.

The regulator's role should be to stress at an early stage that its eventual approval will come only if an adequate stakeholder process has occurred. As part of this stakeholder engagement process, in many cases public utility commissioners or their staff attend the meetings and track progress to ensure that the requesting party-i.e., utility or private transmission company-has performed comprehensive research into why the selected investment (whether a single item or a portfolio of items) is the most sensible. This may be done by first meeting a baseline for policy and reliability requirements and then by prioritizing based on the economic analysis. Although regulatory staff is not obligated to attend, and sometimes simply observe, it is most efficient to keep personnel apprised of decisions made along the way rather than to risk an appeal of many modeling assumptions at the final step in approval.

An example of an investment brought before a regulator may be to increase power system reliability. ${ }^{1}$ This could be in the spirit of maintaining projected compliance with NERC standards. Even reliability fixes can be complex and often have multiple competing solutions. The justifications for this type of investment may involve the results of a power flow modeling study, but typically economics are not introduced into the argument unless there are competitive ways to meet compliance metrics.

Although gaining approval of a reliability project is more simply accomplished in the United States if it has been demonstrated that an ongoing compliance with NERC standards demands it, getting a project approved to facilitate the development of a high-resource area to comply with renewable energy targets is more involved. Typically, many alternatives or sets of alternatives

\footnotetext{
${ }^{1}$ Other needs include generator interconnection, economic upgrades to reduce congestion or improve market access, customer-funded projects, and merchant transmission lines. See Chapter 18 of SENER (2015).
} 
can achieve an objective, and sometimes there are even many sets of objectives. Model computations and analyses to consider many possible paths and time frames to reach a target are done at a stage quite nascent to the official request for approval or disapproval by a regulatory authority.

To elaborate, part of the process of reaching a recommended set of transmission additions requires modeling an assumed set of future generation assets. Choosing which types of generators to use and where they will be located has enormous impacts on the transmission recommendation. In many cases, this is an iterative process. In other words, new generation may be evaluated in the context of a competitive solicitation. The cost of required transmission upgrades to allow the new generation to reach load centers - possibly from distant, high-resource areas in the case of renewables - should be considered as part of the cost of the new generation choices being evaluated. However, the chosen set of generation impacts the transmission system costs. This results in a potentially extensive iterative loop of evaluation. Regulators may want to be involved in that part of the process so that they are comfortable with the resultant choice of assumed future generation that compels the transmission upgrade request.

The regulatory agency has the right to audit the model results and information leading to the approval request. In some cases, commissions run their own power system models to independently verify results. However, due to limited engineering staff resources and limited funds for model software licensing fees, it is more common for public utility commissions to request from the initiating party reruns with different assumptions, more detailed outputs, or auditing of inputs. In Colorado, for example, the initiating party has the right to increase the money they are asking for if the request by the Public Utilities Commission (PUC) to rerun models becomes too onerous.

Although regulators and regulatory staff can be involved in the process and may ask for key questions to be answered, in the end regulatory approval must be justified, objective, and somewhat independent. Below are descriptions of regulatory approval processes in a few states.

\subsection{FERC's Role in Transmission Planning}

At the federal level, in 2011 and 2012 FERC issued Order 1000 and Order 1000-A, respectively, which adopt reforms "to improve transmission planning processes and cost allocation mechanisms under the pro forma Open Access Transmission Tariff (OATT) to ensure that the rates, terms and conditions of service provided by public utility transmission providers are just and reasonable and not unduly discriminatory or preferential" (FERC 2011). Order 1000 builds on Order 890 to correct deficiencies in the transmission planning processes and cost allocation methods. Through Order 1000, FERC aims first to ensure that transmission planning processes at the regional level consider possible transmission alternatives to meet transmission needs more efficiently and cost effectively; and second to ensure that costs are allocated fairly. In the Western Interconnection, the order is expected to facilitate both reliability and renewable integration by requiring transmission owners to participate in intra-regional transmission planning that includes public policy requirements and non-transmission alternatives (Johnson 2015).

Following are the main mandates in Order 1000 with respect to planning (Johnson 2015; FERC 2010a): 
1. Each public utility transmission provider must participate in a regional transmission planning process to help reduce transmission costs.

2. Each public utility transmission provider must establish procedures to evaluate proposed solutions (including non-transmission alternatives) to identified transmission needs. In addition, the evaluation should consider projects that support public policy requirements (such as renewable portfolio standards) in the same arena as reliability projects. To fulfill a public policy requirement, a series of transmission line plans must be developed, estimates of the benefits for each line made, and the projects prioritized. When the best line option is selected, the cost to build that line is to be proportionally shared by the ratepayers. Reliability upgrades are determined in the same manner (Vansant 2012).

3. Public utility transmission providers in neighboring transmission planning regions must coordinate to determine if there are more efficient or cost-effective solutions to their mutual transmission needs.

4. Federal rights of first refusal for certain new transmission facilities are no longer valid. In addition, non-incumbent companies can propose new transmission lines and upgrades to existing lines.

Each public utility transmission provider was required to file compliance with FERC by the end of 2012. For example, CAISO implemented a series of changes to comply with the order, including the addition of a public policy-driven category of transmission elements that enables the independent system operator to identify and approve additions and upgrades needed to meet state and federal policy requirements (CAISO 2012). In addition, CAISO presented a methodology to consider alternatives - such as energy efficiency, demand response, renewable generating resources, and energy storage - to transmission or conventional generation to address local needs in the transmission planning process (CAISO 2013).

\subsection{Texas}

Most of the Texas power market was restructured beginning in 2001. Utilities outside ERCOT continue to operate as vertically integrated monopolies. ${ }^{2}$ Those inside ERCOT were unbundled into separate generation, retail, and delivery companies. Delivery-comprising transmission and distribution — remained regulated by the Public Utility Commission of Texas (PUCT). ${ }^{3}$

In Texas, to build a new transmission line and add its cost into the utility's rate base, ERCOT transmission utilities and Texas utilities outside ERCOT must fill out an application with the PUCT to obtain a Certificate of Convenience and Necessity (CCN). The Public Utility Regulatory Act $\$ 37.056$ establishes that the commission may approve a certificate (within a year of the application filing) only if it is necessary for the service, accommodation, convenience, or safety of the public (PURA 1997). Typically, the PUCT can approve, deny, or modify a proposal. If denied, the PUCT must give a reason, and the applicant could submit an amended proposal. In most cases, an applicant can also seek a rehearing of the original denied application

\footnotetext{
${ }^{2}$ ERCOT serves as an independent system operator managing the flow of electrical power to 24 million customers in the state of Texas, which represents approximately 90\% of Texas's electrical load (FERC 2016).

${ }^{3}$ Municipally owned utilities inside ERCOT had the option to continue operating as vertically integrated utilities. According to the Public Utility Regulatory Act (Ch. 29), rural cooperatives that already separated retail service from generation and transmission were not required to further unbundle transmission operations.
} 
if it thinks the PUCT erred in its rejection. In some cases, the applicant can appeal the rejection to the courts. Typically a change of decision requires the introduction of new evidence that was not considered in the first evaluation (PUCT 2011).

The criteria considered to approve a $\mathrm{CCN}$ are as follows:

1. Adequacy of existing service

2. Need for additional service

3. Effect of granting the certificate on the recipient and on any electric utility serving the proximate area

4. Other factors such as community values, recreational and park areas, historical and aesthetic values, environmental integrity, probable improvement of service or lowered cost to consumers if the certificate is granted, and, to the extent applicable, effect of granting the certificate on the ability of the state to meet the goal of $10 \mathrm{GW}$ of renewable energy in Texas by January 1, 2025, as established by the Public Utility Regulatory Act $\S 39.904$.

The PUCT has specific criteria to assess the applications for CCNs for new transmission lines. These criteria are described in the Electric Substantive Rules for utilities within ERCOT (PUCT 2015), and they are summarized as follows:

1. Determining the extent of the need for the transmission line and its eligibility for rate base treatment

A. For lines that are needed not strictly for reliability but rather to relieve congestion, the applicant must present an economic cost-benefit study that includes an analysis that shows that the levelized ERCOT-wide annual production cost savings attributable to the proposed project are equal to or greater than the firstyear annual revenue requirement of the proposed project of which the transmission line is a part. The applicants - transmission utilities - historically have relied on ERCOT to perform a production cost analysis.

Other important aspects considered by the PUCT include the following

i. Indirect costs and benefits to the transmission systems can be included in the study. ${ }^{4}$

ii. The study has more weight if it is conducted by ERCOT.

iii. The study is not needed for transmission lines that serve competitive renewable energy zones (CREZ) or lines that are necessary to meet state or federal reliability standards.

B. For lines that serve CREZ or are considered necessary to meet state or federal reliability standards, the PUCT considers among other factors the needs of the interconnected transmission systems to support a reliable and adequate network and to facilitate robust wholesale competition. Examples could include lines

\footnotetext{
${ }^{4}$ Typically, ERCOT avoids counting indirect costs and benefits because they can be controversial. However, an example that is included is deferred transmission investment—e.g., for another line.
} 
needed to interconnect a transmission service customer or end-use customer or lines needed for services such as highway transportation, airport construction, public safety, or to improve air or water quality. Also, more weight is given to applications with the following important considerations:

i. Those from organizations that meet the requirement of the Public Utility Regulatory Act $\$ 39.151$

ii. Those with written communications showing that the transmission line is needed to interconnect a transmission service customer or an end-use customer.

2. Determining the route of the line

Selecting one route among alternatives aims to minimize the impact on the affected community unless grid reliability and security dictate otherwise. The PUCT evaluates the impact of the proposed line and decides which route should be approved. Preference is given to routes that

A. Are agreed to by the utility, the landowners whose property is crossed by the proposed line, and the owners of land that contains a habitable structure within 300 feet of the centerline of a transmission project of 230 (kilovolt) $\mathrm{kV}$ or less or within 500 feet of the centerline of a transmission project greater than $230 \mathrm{kV}$

B. Are parallel to existing rights-of-way or utilize an existing right-of-way, including vacant positions on existing multiple-circuit transmission lines, or utilize existing compatible rights-of-way such as roads, highways, railroads, or a telephone utility (PUCT 2011).

C. Conform to the policy of prudent avoidance to limit exposures to electric and magnetic fields with reasonable investments (PUCT 2011).

Landowners who would be affected by a new line can participate by informally filing a protest or participate formally in the case by petitioning to become an intervener party with certain legal rights (PUCT 2011).

Projects that do not require a CCN (and for which these criteria do not apply) include certain extensions, new substations, repairs or reconstruction of transmission facilities due to emergencies, upgrading distribution facilities, and routine activities associated with transmission facilities, among others.

\subsubsection{Competitive Renewable Energy Zones}

CREZ designation is a policy tool for strategically directing new renewable energy development to areas that can provide the greatest benefits to society. Its theory is that renewable energy development will follow the construction of transmission capacity. The key characteristics of an ideal zone for CREZ designation are that its projects are likely to have exceptionally high capacity factors and that potential sites are plentiful enough to ensure robust competition for transmission access among developers of renewable energy projects.

Texas developed the CREZ concept to improve the efficiency of renewable energy development in an organized wholesale power market. Several other U.S. states have adopted the CREZ 
approach with various modifications. Colorado and Minnesota each adopted a modified version of the CREZ approach to inform their transmission planning processes. The Western Governors' Association commissioned an analysis of a multistate Western Renewable Energy Zone that covered the entire Western Interconnection including the portion of northern Baja California connected to CAISO.

\subsubsection{Texas CREZ}

The CREZ model anticipates developing new transmission ahead of developing renewable generation. This is a departure from the usual order of events in U.S. utility regulation. In traditional U.S. practice, planning for a large, thermal, central generating station is concurrent with its transmission because both take the same amount of time to build. Wind and solar generators take much less time to develop, which means that building the needed transmission must begin years before the generation capacity would be installed. Otherwise, wind and solar development could slow down while curtailments of wind and solar generation increase. On the other hand, regulators do not want to burden consumers for transmission facilities that may not be fully utilized. This underscores the importance of a careful examination before a CREZ project is approved.

Because it represents a new approach to transmission expansion, CREZ implementation depends significantly on statutory authority. The Texas CREZ process began as a policy initiative developed by PUCT staff, then in 2005 the Texas legislature revised the criteria (Texas Revised Statutes 35.904) for determining the need for new transmission and financial prudence and for the PUCT to identify renewable energy zones to meet state goals.

In full practice, the steps to identifying CREZs and their associated transmission build-out plans are as follows:

1. Complete a renewable energy resource assessment. Ideally, the assessment should model hourly wind and solar output for a typical meteorological year, and it should reflect geospatial differences with enough granularity to identify areas with relatively high capacity factors. It should also locate known geothermal heat potential. In Texas, this step was done by ERCOT with the assistance of a consulting firm specializing in wind modeling.

2. Using information from the renewable energy resource assessment, identify study areas where capacity factors and production profiles are high. Using geographic information system analysis, develop and apply environmental screens to exclude known sensitive habitat and terrain features that make project development impractical. This step was also done by ERCOT in Texas.

3. Conduct an open season process for potential renewable energy developers to provide tangible demonstrations of commercial interest in specific study areas. In Texas, this step was directed primarily by the regulator, which set criteria for demonstrations of interest.

4. Conduct production cost modeling and a CBA (see Chapter 2) of transmission scenarios that would interconnect the study areas with the highest levels of demonstrated commercial interest. ERCOT conducted both types of analyses on high-capacity, mid- 
capacity, and low-capacity scenarios. The results of these scenarios were then provided to the PUCT for final determination.

5. Select CREZs from study areas with the highest density of screened developable potential, greatest demonstrated commercial interest, and greatest potential for reducing system-wide production costs. This was done by the PUCT based on the studies provided by ERCOT and on comments received from parties in the docket.

6. Approve a transmission build-out plan for the selected CREZs. This was also done by the PUCT after the regulator determined the CREZs.

The outcome of the Texas CREZ process was a collection of new 345-kV lines that enabled high-quality wind zones, alleviated congestion, and improved voltage stability throughout the network (Figure 1). At the state's earliest wind facilities built between 2001 and 2003 in the McCamey zone of West Texas, capacity factors increased to approximately $30 \%$ (from $26 \%$ in 2003 for the same turbines). In the new Panhandle CREZs, new wind turbines installed between 2007 and 2013 achieved an average capacity factor of $45 \%$. 


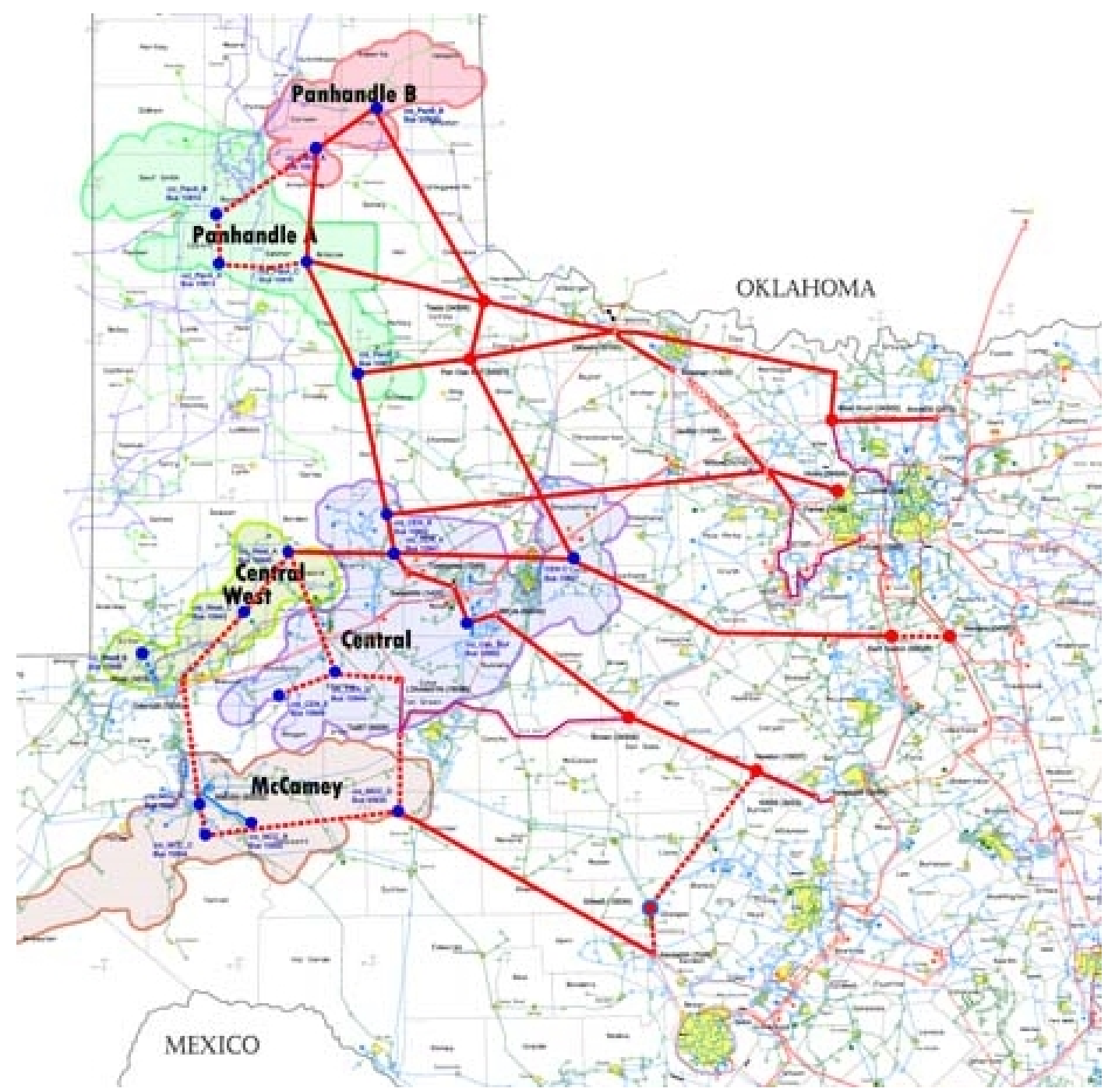

Figure 1. Wind CREZs in ERCOT with 345-kV lines connecting wind to network load. Image from ERCOT (2008)

Variations of the CREZ model have been applied in RTO markets as well as in areas served by monopoly utilities. In both cases, ultimate success depends on the legal and regulatory authority by which CREZ selection leads to an approved transmission plan. A utility or RTO can conduct a technical analysis of potential zones in the absence of a statutory or regulatory directive for transmission approval. In that case, a CREZ informs later options for transmission expansion, but it does not carry legal weight.

\subsubsection{Western Renewable Energy Zone}

In the western United States, analysis related to the Western Renewable Energy Zone has informed plans for direct current (DC) lines of $500 \mathrm{kV}$ or larger to move high-quality wind power across long distances to major load centers without affecting intermediate networks along the way (Figure 2). This is in contrast to the lower-voltage, multiline network upgrades that came out of the Texas process. The technical analysis of resource potential for the Western Renewable Energy Zone initiative was similar to that used in Texas, although it was informed by more 
detailed information due to improvements in wind resource modeling, solar resource modeling, and geographic information system capabilities. The difference was that the transmission solutions identified in the analysis of the Western Renewable Energy Zone involved connections among networks rather than within a single network as was the case in ERCOT.

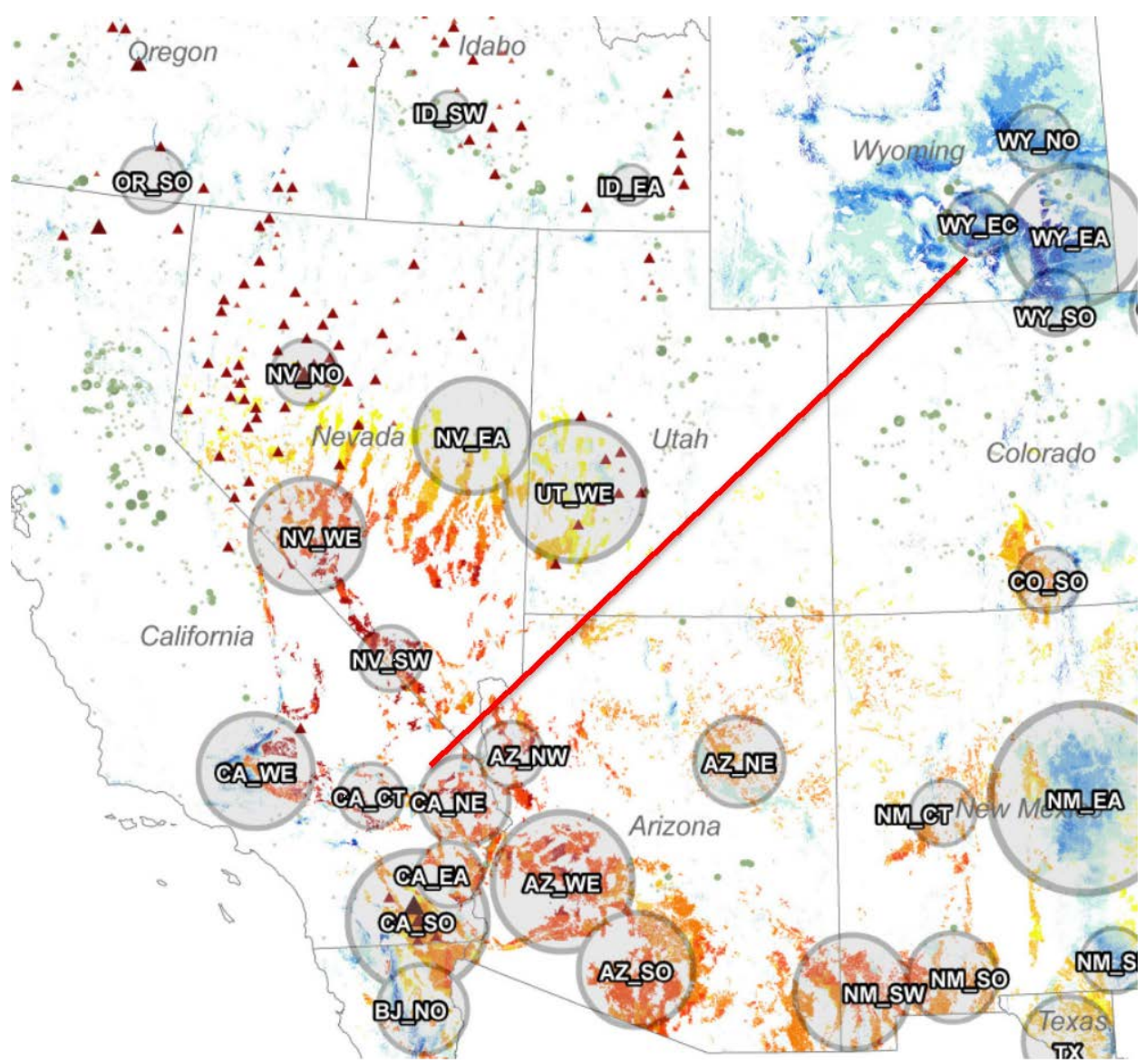

Figure 2. CREZs in the Western United States with proposed 500-kV DC line connecting Wyoming wind to load in California. Image from Western Governors' Association and U.S. Department of Energy (2009) 
A CREZ plan aims to find a balance between abundance and scarcity regardless of whether the problem requires a network solution or one large connection among networks. The transmission plan for a CREZ should be large enough so that economies of scale can reduce costs per megawatthour. At the same time, the zones should contain more developable renewable energy potential than the planned transmission improvements can accommodate so that developers have to reduce their costs to secure an edge over their competitors. Finding the right balance falls to the regulators because the public's interests are significantly different from those of the many private interests involved.

Financing the transmission projects depends on the market structure and industry organization. Typically, transmission projects are funded only by organizations that have long-term staying power and ready access to capital, e.g., utilities. CREZ-type projects depend on whether the regulator is able to preapprove ahead of the time that the capital expenditure investment is "used and useful," the usual regulatory standard for prudent investment. In Texas, approved CREZ lines are included in the base rates of transmission utilities. This spreads the cost throughout the entire ERCOT market based on customer load. Costs are recovered differently in other markets, however. One approach developed in the Southwest Power Pool distinguishes between local and regional upgrades based on the voltage of the new line. If a line element is $345 \mathrm{kV}$ or greater, costs are recovered regionally; lower voltages are regarded as upgrades with local reliability benefits and are allocated to the local utility for inclusion in its rates. ${ }^{5}$

Another option is for a generation developer to simply include long-distance transmission as an extraordinary project cost. A key regulatory issue in the United States is whether the developer also intends to sell transmission access to other generators. Under U.S. practice, this would cause the developer to be regarded as a transmission utility subject to rules for open access, nondiscriminatory tariffs, and other regulatory requirements placed on all transmission utilities.

In some cases, the transmission utility can seek approval for a separate tariff applicable only to generators connecting to a certain line. This enables directly allocating costs to the generators that benefit rather than allocating costs among all loads served by the utility.

\subsection{California}

CAISO has three investor-owned utilities as members and controls approximately $75 \%$ of the transmission lines in the state of California and some transmission in a small part of Nevada

\footnotetext{
${ }^{5}$ (1) The costs of facilities operating at $300 \mathrm{kV}$ and above will be allocated $100 \%$ across the Southwest Power Pool region on a postage-stamp basis. (2) The costs of facilities operating above $100 \mathrm{kV}$ and below $300 \mathrm{kV}$ will be allocated one-third on a regional postage-stamp basis and two-thirds to the zone in which the facilities are located. (3) The costs of facilities operating at or below $100 \mathrm{kV}$ will be allocated $100 \%$ to the zone in which the facilities are located. See FERC (2010b).
} 
(CAISO 2016). It serves approximately $80 \%$ of the electricity demand in California. The remaining $20 \%$ is served by eight other balancing authorities, including PacifiCorp and the Los Angeles Department of Water and Power. Thus, the transmission planning process in California depends on the specific authority. CAISO has conducted a statewide conceptual transmission plan on behalf of the State of California that intends to support the 33\% renewable energy goal by 2020 while addressing reliability needs. The 2014-2015 conceptual transmission plan incorporates information from past analyses of the California Transmission Planning Group and the 2015 WestConnect Annual Ten-Year Transmission plan (CAISO 2015a).

In California, new transmission has to be approved by both CAISO and the California Public Utilities Commission (CPUC). Before reaching the CPUC for final approval, CAISO is responsible for evaluating the need for all potential transmission upgrades (CAISO 2004), including the evaluation of alternative resources. CAISO established a methodology to identify economic projects that promote efficient utilization of the grid called Transmission Economic Assessment Methodology (TEAM). It is intended to be adopted by market participants, regulatory agencies, and other stakeholders. TEAM covers the following:

1. A benefit framework consisting of economic benefit estimates from different perspectives - e.g., ratepayers, independent system operator participants, or the entity in charge of monitoring compliance and enforcing reliability standards (such as the Western Electricity Coordinating Council). Benefits can also be classified into those that impact consumers, producers, transmission owners, and the total system. The goal is to assess the economic benefits of transmission lines considering all perspectives.

2. A network representation

3. Market price assessment

4. Uncertainty analysis

5. Resource alternative. In 2013, CAISO proposed a new methodology to support California's emphasis on the use of non-transmission alternatives - e.g. energy efficiency, demand response, renewable generating resources, and energy storage. The previous approach examined the effectiveness of each proposed alternative on a case-bycase basis, which was labor intensive and did not provide criteria in advance for potential developers. The new proposed methodology is to identify "in advance the needed performance characteristics and load profile impacts that non-conventional solutions should be able to provide to effectively defer or eliminate the need for particular transmission additions" (CAISO 2013).

The TEAM methodology is described in more detail in Chapter 2. For an example of the methodology applied to a project, see Chowdhury and Le (2009).

For all transmission upgrade studies, the minimum requirement is to use a transmission network model and consider alternative resources. The categories of transmission additions considered by CAISO in its transmission planning process are based on the following objectives:

1. Reliability: Maintain reliability of the transmission system (local planning areas and the bulk power system). 
2. Policy-driven: Integrate the renewable energy generation according to the state's renewable portfolio standard into the transmission system.

3. Economic: Perform an economic assessment of potential transmission projects.

\subsubsection{California Public Utilities Commission's Certificate of Convenience and Necessity Process}

The CPUC is in charge of approving permitting applications for new transmission lines. The California public utilities code Section 1002 (see CPUC [2015a]) establishes that if the new transmission line requires a certificate according to Division 15, Section 25000 (the WarrenAlquist State Energy Resources Conservation and Development Act) of the public resources code that the certificate shall be obtained first and effectively take the place of the CCN requirements. In addition, lines less than $50 \mathrm{kV}$ are considered distribution projects, and in general they do not require a CCN. Lines from $50 \mathrm{kV}-200 \mathrm{kV}$ require a permit to construct, which is mainly governed by the California Environmental Quality Act, and the CPUC does not analyze these projects further.

By law under the public utilities code Section 1001 (see CPUC [2015a]), investor-owned utilities are required to obtain a permit from the CPUC to construct new transmission lines. The utility or applicant has to do the following:

1. File an application with the CPUC requesting approval to construct a specific transmission line. This opens a proceeding, and the commission assigns an administrative law judge and a commissioner to run the proceeding.

2. Post notices of its application to governments, the local newspaper, and in the local area of the project. A formal notice has to be sent to landowners within 300 feet of the project right-of-way. The administrative law judge might require the utility to send additional notices.

A. A 30-day protest period from the filing date allows businesses, residents, consumer groups, etc., to protest the application. If the application is not protested or protests are withdrawn, the application is considered uncontested. If it is protested, the administrative law judge holds hearings.

3. File a Proponent's Environmental Assessment that describes the project and its potential environmental impacts. (See left side of scheme in Figure 3.)

A. The Energy Division of the CPUC reviews the Proponent's Environmental Assessment as required by the California Environmental Quality Act.

i. Testimony proceedings and evidentiary hearings take place. These public meetings focus on environmental issues and are held in communities close to the projects. Parties serve expert witness testimony to the proceedings to address the need for the project and alternatives. At the conclusion of the evidentiary hearings, parties file briefs regarding the conclusions the CPUC should reach in the proceeding.

ii. The administrative law judge receives a final report called an Environmental Impact Report or Mitigated Negative Declaration. 
4. Provide a review of project needs and costs according to the public utilities code Section 1001 and the General Order $131-\mathrm{D}^{6}$ that grants the $\mathrm{CCN}^{2}$ or permit to construct. (See right side of scheme in Figure 3.)

A. The California public utilities code Section 1002 (see CPUC [2015a]) establishes that the basis to grant a certificate need shall give consideration to four factors:

i. Community values

ii. Recreational and park areas

iii. Historical and aesthetic values

iv. Influence on environment.

B. To grant the CCN for projects greater than $200 \mathrm{kV}$, the CPUC analyzes the corresponding need (from a reliability and/or economic standpoint) as well as the environmental impacts of a proposed project. The following examples demonstrate the general methodology used to assess these metrics:

i. Need of the transmission project. "Examine the applicant's assertion of why the project is needed. If the project is claimed to be needed for reliability purposes, the Commission will analyze reliability. For example, in the case of PG\&E's [Pacific Gas and Electric's] application for its Jefferson-Martin line, the Commission looked at issues including load forecasts, local generation capacity, other transmission capacity, and the potential for distributed generation and demand reductions. These issues were analyzed using load serving capability studies (by CAISO) and power flow analyses (by PG\&E), and by applying industry-standard reliability criteria" (CPUC 2009). In this case, the independent system operator's reliability criteria incorporated national NERC and regional Western Electricity Coordinating Council planning standards as well as local reliability criteria - in particular, certain modifications for the San Francisco peninsula area (CPUC 2004a; CPUC 2004b). The independent system operator's grid planning standards include reliability criteria for forecasted operations under different system conditions (CPUC 2004a). For more information about the assessment of need in general-including system, local, and flexible needs - see the CPUC Long Term Procurement Plan wherein the CPUC looks 10 years ahead by considering the Energy Commission demand forecast and CAISO's assumptions for transmission planning (CPUC 2016).

In addition, "more recently, lines have been proposed as needed for interconnecting with new sources of renewable generation, and the Commission has accordingly analyzed this basis for the need for transmission lines. For example, in response to SCE's [Southern California Edison's] application for part of its Tehachapi 4 project, the

\footnotetext{
${ }^{6}$ The Commission issues decisions of general applicability in the form of general orders. General Order 131-D specifically addresses the procedures to be followed in applications for siting electric transmission infrastructure. It implements public utilities code Section 1001 in the context of electric transmission projects.
} 
Commission identified and considered specific renewable energy projects that would utilize the line, as well as the potential for additional renewable energy generation in the Tehachapi area" (CPUC 2009).

ii. Economics of the project: "If the project is claimed to be needed for economic reasons, the Commission will analyze the economics of the line. In approving SDG\&E's [San Diego Gas and Electric's] application for its Miguel-Mission line, the Commission reviewed and considered CBAs that looked at various factors, including project construction costs, reduced congestion management costs, and the effect of additional generation."

iii. Environmental impacts of the project.

If a project is rejected because of non-compliance with established reliability or economic criteria, an applicant can typically request a rehearing, reargument, or reconsideration with the same regulator. The applicant will have an opportunity to explain how the commission erred in its original decision. Whether to rehear a case is at the discretion of the regulator. If a rehearing is granted, it usually means that the regulator has been convinced that there was an error in the original decision.

Typically, an applicant can come back to the regulator with a revised proposal that will get a new hearing and start the process again. Applicants can always challenge a regulator's decision in court; however, often this is not successful because the courts give a lot of deference to the regulator, and also the judicial appeal takes a long time.

After review, the administrative law judge reaches a final proposed decision (see Figure 3), which is mailed to the commission. Individual commissioners have the option of preparing proposed decisions of their own (which are alternate decisions). At least 30 days after the proposed decision is mailed to the commissioners, they should vote on the decision. The commission may reject or accept a proposed alternate decision or change it in any way. Figure 4 shows the historic permitting timeline from the moment the application is deemed complete. 


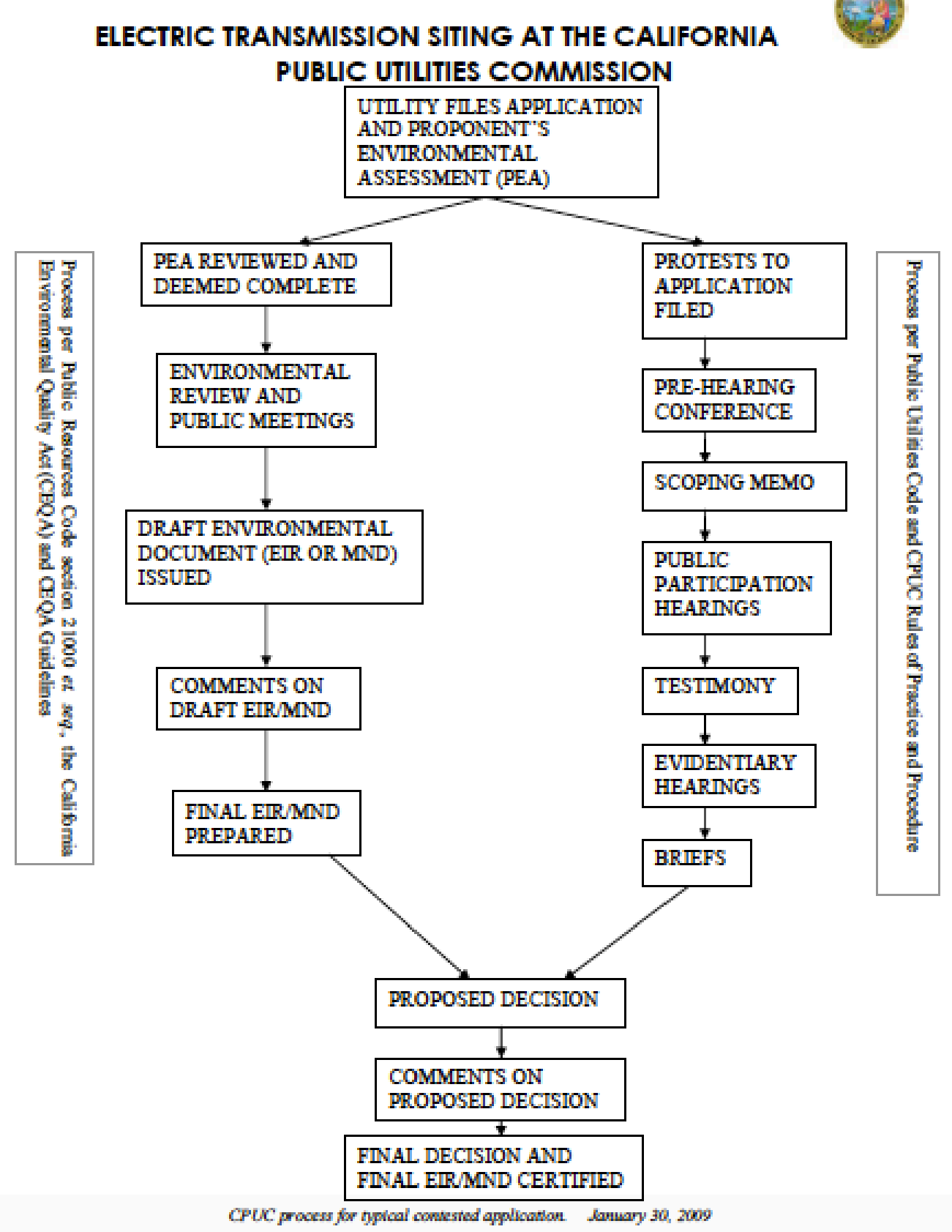

Figure 3. CPUC process for a new transmission line permit. Image from (CPUC 2009) 


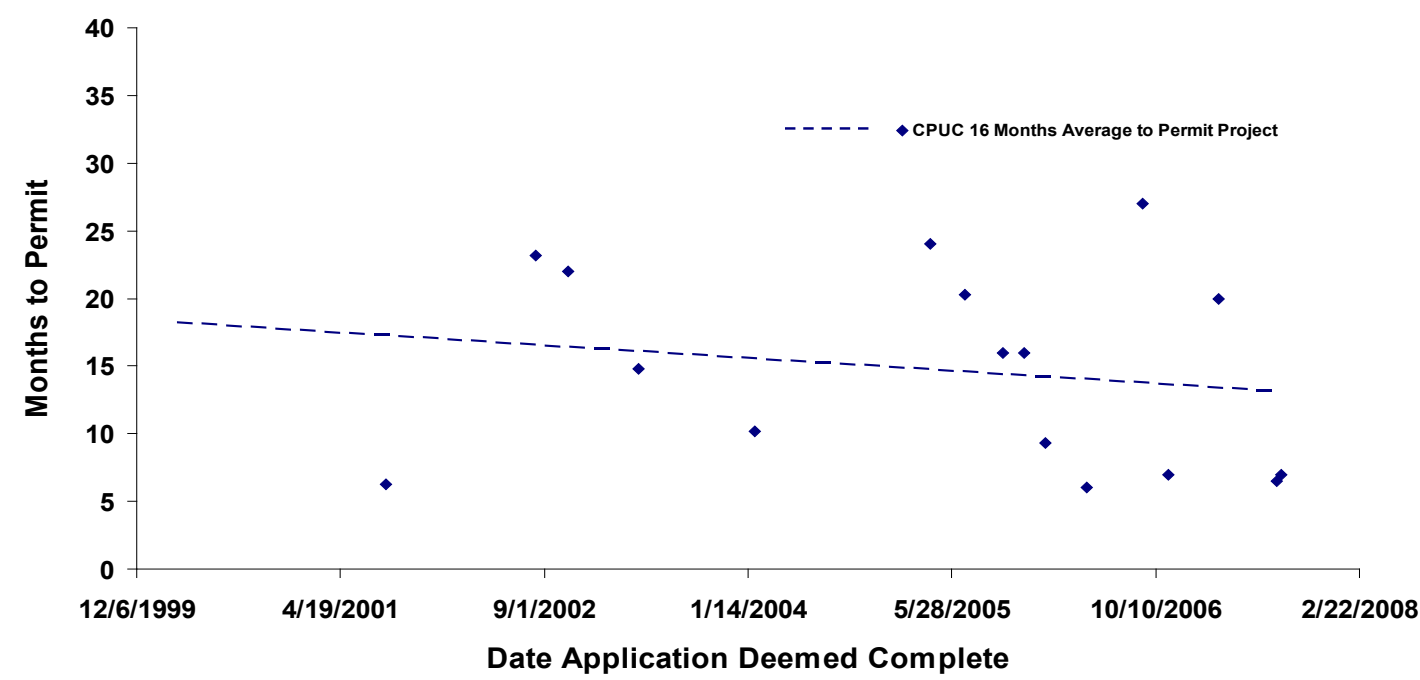

Figure 4. Historic permitting timeline at CPUC. Project time is taken from application deemed complete to a commission decision. Image from Transmission and Environmental Permitting Team of CPUC (2009)

\subsection{Colorado}

In Colorado, the PUC regulates only investor-owned utilities. If an upgrade is not in the ordinary course of business, a utility must obtain a Certificate of Public Convenience and Necessity (CPCN) (see Colorado PUC [2015]) pursuant to the Colorado Revised Statutes \$40-5-101. Each year, the commission staff reviews the utilities' lists of projects asserted to be "in the ordinary course of business" and advises the utilities of the staff's opinion of the list. In this way, utilities receive guidance about which projects will require a CCN. Projects that fall under the ordinary course of business include upgrades to and construction of distribution lines that meet the approved limits for noise and magnetic field and transmission lines that are less than $230 \mathrm{kV}$. Thus, utilities can proceed to implement such projects and adjust rates to recover their investments without obtaining additional approval from the PUC. Projects for lines that are greater than $230 \mathrm{kV}$ or lines that are $115 \mathrm{kV}$ and $138 \mathrm{kV}$ that do not meet the noise and magnetic limits are not considered in the ordinary course of business and require an application to the PUC for a CPCN from the PUC. The application needs to include costs of the project, construction period and in-service date, alternatives that were considered, criteria for their selection, and a report of prudent avoidance. ${ }^{7}$ In addition, the application must include a description of actions and techniques relating to cost-effective noise mitigation with respect to the planning, siting, construction, and operation of the proposed transmission or extension.

For an example of a CPCN, see Tri-State Generation and Transmission Association, Inc. (2010).

Colorado's PUC electric rules also define considerations to evaluate the existing and additional transmission resources. In particular:

\footnotetext{
${ }^{7}$ Prudent avoidance refers to reducing human exposure to magnetic fields at a reasonable cost.
} 
- The utilities must report existing transmission capabilities and future needs during the planning period for lines that are $115 \mathrm{kV}$ and above.

- Pursuant to the Colorado Revised Statutes $\S$ 40-2-126, the utilities must submit a description of all transmission lines and facilities that could be placed into service during the period of resource acquisition. ${ }^{8}$ For each line, utilities must submit the following information intended to be used for resource planning and bid evaluation purposes:

$\circ$ Length and location, estimated in-service date, injection capacity, estimated costs, terminal points, voltage and MW rating

- The costs required or imposed on the system and the transmission benefits so that the commission can equitably compare possible resource alternatives.

Utilities are requested to submit a 10-year transmission plan identifying facilities of $100 \mathrm{kV}$ or greater by no later than February 1 each year. This plan is intended to provide information to the PUC and to require utilities to notify stakeholders that are affected. In this way, the PUC tries to guarantee that the CPCN applications received will be for projects that have overcome any potential opposition from stakeholders and local parties - i.e., this process ensures that the PUC is evaluating only projects that are highly likely to be implemented.

The proposed projects must:

1. Not negatively impact the system ${ }^{9}$

2. Avoid duplication of facilities

3. Reflect the development of joint projects when a proposed project services the mutual needs of more than one transmission provider and/or stakeholder.

In addition, 10-year plans must comply with reliability criteria, all legal and regulatory requirements, and must be consistent with applicable transmission planning requirements in FERC Order 890 and Order 1000 (see FERC [2011]), which requires planning based on open, transparent, and coordinated processes. Finally, 10-year plans must demonstrate the efficient utilization of the transmission system on a best-cost basis. ${ }^{10}$

${ }^{8}$ Resource acquisition refers to new generation capacity.

${ }^{9}$ Specifically, “... not negatively impact the system of any other transmission provider or the overall transmission system in the near-term and long-term planning horizons." NREL interprets this to mean in the context of reliability or contingency planning.

${ }^{10}$ The best cost balances cost, risk, and uncertainty, and it includes proper consideration of societal and environmental concerns, operational and maintenance requirements, consistency with short-term and long-term planning opportunities, and initial construction cost. 


\section{Cost-Benefit Analysis}

Many regulatory bodies in the United States have statutory directives to ensure that all costs passed on from utilities to customers are financially prudent. This includes transmission. Consequently, a utility must be able to demonstrate to its regulators that the costs of a project for which it seeks approval are reasonable. ${ }^{11}$ For merchant projects, developers have to demonstrate to prospective equity partners and lenders that the economic fundaments of a project support a likelihood of profitability.

A CBA is a tool for testing the financial prudence of a proposed project — not only transmission but new generation as well. It is used primarily to decide whether to proceed with a transmission project intended to relieve system congestion and reduce the cost of delivering power (often called economic projects). It can also help evaluate options for maintaining reliability or for meeting policy objectives when the need is not in question but the most cost-effective solution is.

Mexico's regulators could use a CBA framework to standardize part of the transmission decision process. Over time, it creates predictability and familiarityfor stakeholders as well as decision makers - with respect to an important subset of issues common to many transmission proposals. Although a CBA's results are rarely the sole basis for a decision, it can provide a methodologically sound foundation from which other issues can be evaluated with greater focus.

A CBA mathematically compares the expected cost of a capital expansion project to the likely benefits attributable to the project. It is limited to factors that can be measured in monetary terms. This means that nonmonetary factors, if regulators determine they should be considered, must be evaluated by some other means or must be approximated by some monetary equivalent. If a nonmonetary benefit is embodied in policy, the policy itself can serve as a boundary condition for the CBA. In this case, the CBA then becomes a tool for finding the most cost-effective way to achieve the policy.

${ }^{11}$ If costs later exceed what regulators have approved, the utility has the burden of proving that a lack of prudence was not the reason for the overruns. If it cannot demonstrate prudence, the utility absorbs the additional costs without rate recovery.

\section{Repair or Replace Decision Making}

According to Winsor and Buncombe (2007), asset management practices include deciding when to replace equipment versus repair equipment. The best decision will come from an algorithm involving expected life-cycle costs of both choices, with an incorporated risk profile of failure. The more information that can be provided as input into the analysis, the better the decision output. Data includes:

- Age of equipment

- Annualized cost of refurbishment

- Annualized cost of replacement.

With this information, a cumulative graph comparing cost to age graph can be drawn. The tangent to the curve provides the optimal time to replace the asset. See https://amcouncil.com.au/files/Asset_Manageme nt_Council_0902_ICOMS_2007025.pdf.

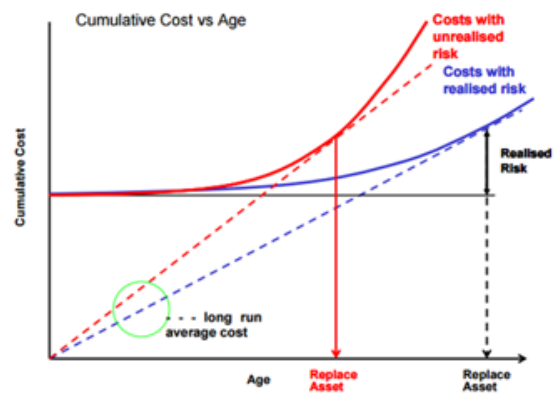

Figure 5. Optimal replacement age. Image from Winsor and Buncombe (2007) 
The result of a CBA is expressed as a benefit-to-cost ratio. This metric can carry great weight in the regulatory decision about whether to approve a proposed project. Mathematically, a ratio greater than 1.0 means that the measured economic benefits exceed the expected costs. A ratio less than 1.0 means that the projected costs are more than the sum of the measurable likely benefits. $^{12}$

Because the accuracy of a benefit-to-cost ratio depends on simplifying assumptions and projections of future conditions, ultimately the interpretation of any benefit-to-cost ratio is at the discretion of the regulatory decision maker. If the CBA is conducted in a transparent manner, however, the decision makers can invite stakeholders to comment on the results and then synthesize the input to arrive at a final decision on the proposed project. The regulator could also establish an indicative benchmark for benefit-to-cost ratios, but these are binding only to the extent the decision maker deems them to be. ${ }^{13}$

A transmission project's costs and benefits accrue during the course of decades, so elements that enter into the CBA are calculated on a net present value (NPV) basis. Components of the calculation are:

$$
\text { benefit-to-cost ratio }=\frac{\sum_{\mathrm{i}} \text { NPV of attributable benefit } \mathrm{i}_{\mathrm{i}, \mathrm{T}, \mathrm{r}}}{\text { NPV of project } \operatorname{cost}_{\mathrm{T}, \mathrm{r}}}
$$

where

- The NPV of all elements is calculated over the same period of time, $T$, using a common discount rate, $r$.

- Project cost is the all-in cost of adding the infrastructure.

- Attributable benefit is a discrete change in value that is caused by the project.

- $i$ designates a distinct type of attributable benefit for which the NPV is calculated separately.

Independent power producers and merchant transmission providers will also use a CBA in their project financials. A CBA applied to a private investment often focus more narrowly on the costs and benefits that directly affect the project's ability to provide a return on equity to the project's investors.

The set of relevant costs and benefits can differ depending on whether the project is viewed from a private perspective or a social perspective. For example, if only part of a project's costs are to be recovered from ratepayers, one iteration of the CBA would compare all the quantifiable social benefits - for example, wholesale power prices, reliability, and emission reductions - to only the

\footnotetext{
12 The outcome may also be expressed as the simple difference between benefits and costs: generally favorable if benefits are larger and the difference is positive and generally unfavorable if the difference is negative.

${ }^{13}$ FERC uses a threshold of 1.25 for benefit-to-cost ratios. FERC's directive, however, is not rigid: “A transmission planning region or public utility transmission provider may want to choose such a threshold to account for uncertainty in the calculation of benefits and costs. If adopted, such a threshold may not include a ratio of benefits to costs that exceeds 1.25 unless the transmission planning region or public utility transmission provider justifies and the Commission approves a greater ratio" (FERC 2011 ).
} 
portion of costs that would be included in the utility's rate base. The share that would be privately financed would be compared to the private benefits.

\subsection{Net Present Value: Discount Rate and Time Horizon}

Deciding what to use as a discount rate is important to the CBA outcome. A high discount rate places greater weight on near-term costs and benefits, whereas a low discount rate gives future costs and benefits relatively more weight. The discount rate captures the time value of money, but it also quantifies factors that are more subjective. Such factors could include the regulator's estimation of intergenerational trade-offs (that is, how society values benefits and costs for future generations), the uncertainty of estimated costs and benefits in outlying years, and the potential influence of future disruptive technologies.
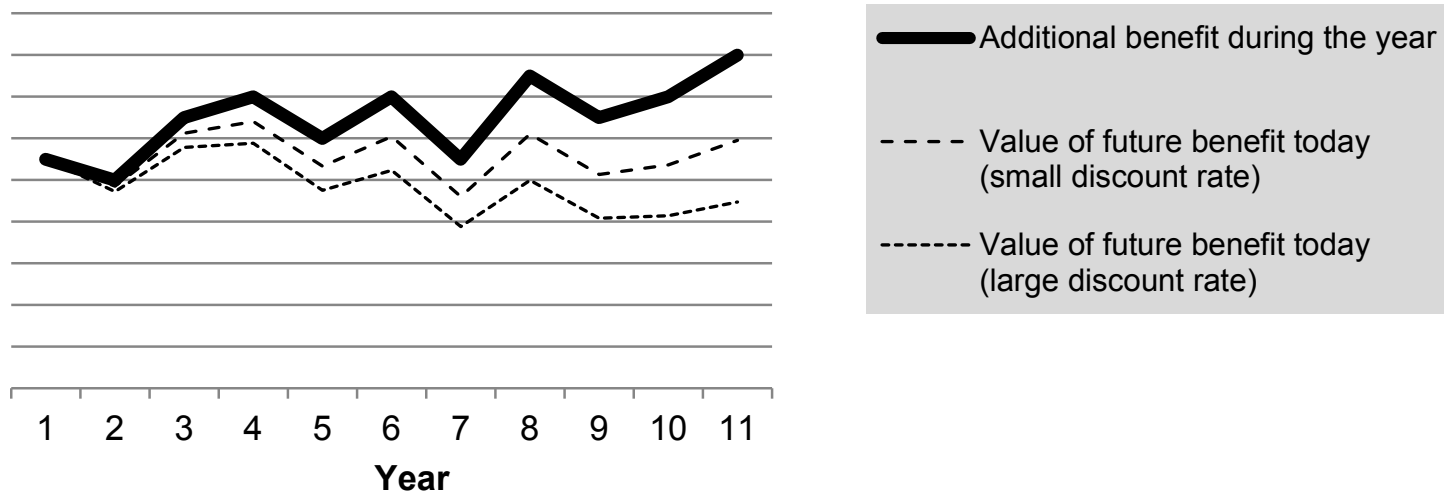

Figure 6. Effect of discount rate on value of future benefits

A regulatory agency may decide on a standard discount rate to be used in all CBAs. A commonly used discount rate is the utility's weighted average cost of capital. Sometimes regulators consider a "societal" discount rate, which is more or less equal to the economy-wide real interest rate and is lower than private costs of capital. Having a standard discount rate may reduce the likelihood that the discount rate will arise as a contested issue in a subsequent legal proceeding for a specific project. It also provides some measure of consistency among similar regulatory proceedings. Setting a standard discount rate in its own special proceeding would focus attention on the rate itself without the potential for being skewed by the particular circumstances of a specific case. The regulatory agency may also elect to have an independent academic expert recommend a discount rate and allow parties to comment on the recommendation.

The time period during which a CBA is calculated should coincide with the economic life span of the project being evaluated. (Project life span can be a function of how long capital costs are financed or on the period during which the asset is scheduled to be fully depreciated if the two time periods are different.) U.S. utilities commonly assume a 40-year economic life span for high-voltage transmission projects.

In some circumstances, the CBA might have to account for factors that have a shorter economic life span than the transmission asset. A transmission line to a renewable energy zone might have an economic life span of 40 years, but the renewable energy generators enabled by the new line might have an economic life span of only 20 or 30 years. The CBA would need to clarify what it 
assumes will happen once the renewable resources retire. If they are not replaced, they cannot count as economic benefits for later years. If they are replaced, the CBA should include assumptions about the cost and efficiency of those future assets.

\subsection{The Denominator: Project Costs}

Only those costs associated with building the project being examined enter into the denominator's NPV calculation. For a transmission line, this would include the capital cost of the asset (sometimes called overnight cost), the cost of obtaining a right-of-way, permitting and other regulatory approvals, construction costs such as labor, and the cost of financing. All of these costs apart from financing are considered "project costs" that are financed over time with a combination of debt and equity.

Table 1. Categories of Potential Benefits from Transmission Expansion

\begin{tabular}{|c|c|}
\hline Category & Benefit \\
\hline \multirow[t]{10}{*}{ Production Cost Savings } & Production cost savings as traditionally estimated \\
\hline & Reduced transmission energy losses \\
\hline & Reduced congestion due to transmission outages \\
\hline & Mitigation of extreme events and system contingencies \\
\hline & Mitigation of weather and load uncertainty \\
\hline & $\begin{array}{l}\text { Reduced cost due to imperfect foresight of real-time system } \\
\text { conditions }\end{array}$ \\
\hline & Reduced cost of cycling power plants \\
\hline & $\begin{array}{l}\text { Reduced amounts and costs of operating reserves and other } \\
\text { ancillary services }\end{array}$ \\
\hline & Mitigation of reliability must-run conditions \\
\hline & $\begin{array}{l}\text { More realistic representation of system utilization in Day } 1 \\
\text { markets }\end{array}$ \\
\hline \multirow{3}{*}{$\begin{array}{l}\text { Reliability and Resource } \\
\text { Adequacy Benefits }\end{array}$} & Avoided/deferred reliability projects \\
\hline & Reduced loss-of-load probability \\
\hline & Reduced planning reserve margin \\
\hline \multirow{3}{*}{$\begin{array}{l}\text { Generation Capacity Cost } \\
\text { Savings }\end{array}$} & Capacity cost benefits from reduced peak energy losses \\
\hline & Deferred generation capacity investments \\
\hline & Access to lower-cost generation resources \\
\hline \multirow[t]{2}{*}{ Market Benefits } & Increased competition \\
\hline & Increased market liquidity \\
\hline \multirow[t]{2}{*}{ Environmental Benefits } & Reduced emissions of air pollutants \\
\hline & Improved utilization of transmission corridors \\
\hline Public Policy Benefits & $\begin{array}{l}\text { Reduced cost of meeting public policy goals such as } \\
\text { renewable targets }\end{array}$ \\
\hline
\end{tabular}




\begin{tabular}{|ll|}
\hline Category & Benefit \\
\hline $\begin{array}{l}\text { Employment and Economic } \\
\text { Development Benefits }\end{array}$ & $\begin{array}{l}\text { Increased employment and economic activity, increased tax } \\
\text { revenues }\end{array}$ \\
\hline $\begin{array}{l}\text { Other Project-Specific } \\
\text { Benefits }\end{array}$ & $\begin{array}{l}\text { Storm hardening, increased load-serving capability, synergies } \\
\text { with future transmission projects, increased fuel diversity, } \\
\text { increased resource planning flexibility, increased wheeling } \\
\text { revenues, increased transmission rights and customer } \\
\text { congestion-hedging value, high-voltage DC operational } \\
\text { benefits }\end{array}$ \\
\hline
\end{tabular}

Information compiled from Pfeifenberger, J., J. Chang, and A. Sheilendranath (2015)

Project costs may be simplified and modeled assuming a constant revenue requirement every year of the project's economic life. However, the NPV calculation can take into account future changes in total costs if they are known. Planned maintenance costs, for example, can be separated from project costs and assigned to the years they are expected to arise.

Costs that are external to the project are not included in the denominator. These could include environmental impacts or new reliability impacts that would need to be addressed through greater use of reserves. For the purposes of a CBA, external impacts are not counted as project costs; rather, they are considered "benefits" with negative value that count against all other positive-value benefits in the numerator.

Nevertheless, some external impacts can be internalized if the project includes mitigation. A transmission route might encroach on environmentally sensitive habitat, for example, in which case the impact would count as a negative benefit. However, if the developer agreed to mitigation measures (such as to purchase and set aside land elsewhere), the mitigation costs could be included in the project costs. This essentially moves the related environmental impacts from the CBA numerator where they are a negative benefit to the denominator where they add to the project cost. ${ }^{14}$

\subsection{The Numerator: Attributable Benefits}

Attributable benefits include the economic value of all effects that would occur if and only if the project is built. The scope of benefits can be broad provided they can be quantified, monetized, and shown to be caused by building the project.

Production cost savings is a common benefit used in a transmission project's CBA. Often the reason for building a new line is to relieve transmission congestion and enable more dispatch from low-cost units. These effects can be captured in production cost modeling, which can compare system costs with the new line to system costs without it.

The numerator can also include reliability benefits. For example, consider an old generator that would normally be retired but is instead kept available as a reliability must-run unit because of its location on a particularly weak part of a grid. Keeping the unit on standby involves known costs, and deploying it when needed can often incur above-market costs that can be measured.

\footnotetext{
${ }^{14}$ In this example, the environmental impacts addressed by the mitigation paid through project costs should be removed from the numerator to avoid double counting.
} 
An important part of the value from a proposed transmission upgrade could be to eliminate the need for keeping the old unit on reliability must-run status. This would be a benefit — apart from and in addition to the production cost savings - included in the CBA numerator. ${ }^{15}$

Table 1 lists several types of benefits that could be included in a CBA. Some are readily quantifiable and easily included in the analysis. Others are more subjective or involve nonmonetary metrics.

Whether a benefit-to-cost ratio is above or below 1.0 can depend on benefits that respond to factors such as the future price of natural gas. This can have a particularly large impact on benefits associated with production cost savings, especially if natural gas is a large part of the system's total generation mix. A CBA can include a sensitivity analysis to test the robustness of its conclusions. Sensitivity analyses are very helpful to regulators especially in informing the discretion exercised by the commission in interpreting the cost-benefit analysis. For example, production cost modeling can include one set of runs that assume high natural gas prices and another set using low natural gas prices and holding all other assumptions unchanged. The two sets of values can be interpreted as a plausible range of future production cost savings resulting from the project that account for possible changes in the price of natural gas.

Figure 7 illustrates a two-factor sensitivity analysis. The CBA examined long-distance transmission to deliver wind power from Wyoming to southern Nevada and California. The two uncertainties captured in this sensitivity analysis were the future cost of renewable technologies and whether a line from Wyoming to California would eliminate the need to build other transmission within California. Instead of making a summary judgment about which assumption to use, the CBA tested variations in both. In this case, all of the benefit-to-cost ratios were well above 1.0, indicating that the findings were robust to future uncertainties about future renewable technology costs and about whether or not other transmission costs could be avoided.

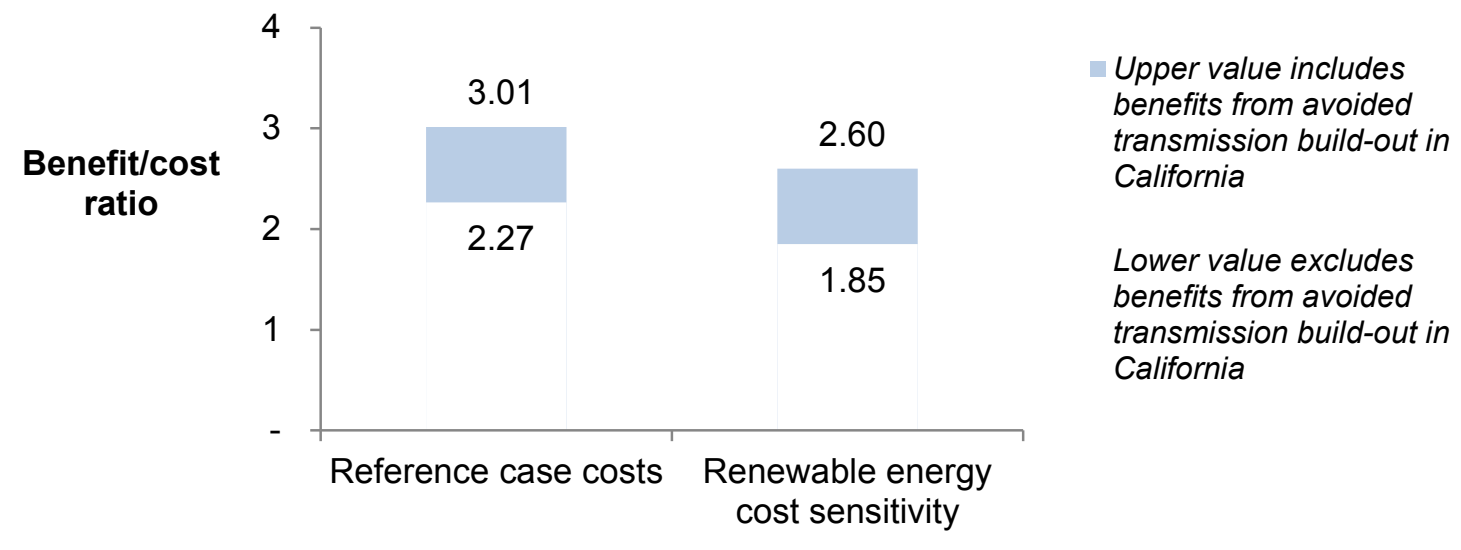

Figure 7. Sensitivity analysis of future renewable energy costs and avoided transmission. Image from Corbus et al. (2014)

\footnotetext{
${ }^{15}$ In another example, reliability impacts indicated by the calculated change in expected load-carrying capability (effective load-carrying capacity is explained later in this paper) were monetized using the cost of a new natural gas combustion turbine (Western Governors' Association and U.S. Department of Energy 2009).
} 


\subsection{Application}

As an example of application, CAISO has three categories of transmission expansion: those necessary for basic reliability, those that help meet policy goals in the most cost-effective manner, and those that generally reduce system costs and help market efficiency. As noted above, CAISO uses a CBA framework called TEAM to evaluate the economic impacts of new lines and transmission upgrades.

TEAM includes five key principles for quantifying costs and benefits: the benefit framework, network representation, market prices, uncertainty, and the principle of alternative resources (CAISO 2008). This summary discusses the role of each in the TEAM analysis.

\subsubsection{Benefit Framework}

TEAM establishes a consistent structure to evaluate the benefits and costs of transmission upgrades as they relate to consumers, generators, and transmission owners using the subset of costs and benefits most applicable to each of these groups. CAISO employs this approach to have a better understanding of how costs or benefits are distributed among the market participants. Only upgrades that demonstrate more benefits than costs to CAISO ratepayers can be recommended for approval.

Transmission upgrades can have a range of benefits for customers, but CAISO only quantifies direct benefits as they relate to decreases in generation and capacity costs. CAISO evaluates the impact of transmission upgrades in shifting load from one pathway or certain generators to others. The goal is to capture the extent to which a transmission upgrade reduces locational marginal prices and if this results in a net benefit for ratepayers.

Ratepayers may also benefit from transmission upgrades that allow out-of-state capacity to serve CAISO capacity or resource adequacy requirements. Gauging capacity benefits requires an analysis of locational marginal price variation as well as an analysis of resource deficiency potential to determine whether that price difference can be reasonably expected to continue.

The scope of these benefits is generated through production cost simulations and power flow analyses of the $5^{\text {th }}$ and $10^{\text {th }}$ planning years. Total benefits from the $10^{\text {th }}$ planning year are extended throughout the economic life span of the project with no assumed benefit escalation after the $10^{\text {th }}$ year.

In its transmission expansion plan for 2014 and 2015, CAISO aggregated the inflation-adjusted benefits throughout the economic life span of the transmission project (40-50 years). It also repeated the NPV calculation using different discount rates (5\% and 7\%) that tested the sensitivity of the results to different weighting of future impacts (CAISO 2015b).

CAISO then compared these benefits to the total cost or revenue requirement of a new transmission project. CAISO does not have the necessary information available to determine the exact revenue requirements for specific projects so they generate an expected revenue requirement by multiplying the capital cost estimate by a capital cost to revenue requirement multiplier of 1.45. They also assume: 
- The asset depreciates over 50 years.

- The project's return on equity is $11 \%$.

- Inflation, property tax, and operating and maintenance costs increase $2 \%$ per year.

\subsubsection{Network Representation}

Adequately capturing the net benefit of a transmission project requires making assumptions about future electricity costs within CAISO and the western market interconnection. To more accurately reflect the future benefits of a transmission upgrade, CAISO requires computer modeling that can forecast physical flows, dispatch, and nodal prices on the transmission network on an hourly basis.

The goal of the modeling is to determine the variation in wholesale power pricing and generation dispatch resulting from a transmission upgrade compared to a future without the upgrade. Critical inputs to the model include projections for future electricity demand, natural gas prices, hydroelectric generation, and new generation. CAISO does not require the use of specified data sources for these forecast inputs; rather, they are determined and justified by the experienced user.

\subsubsection{Market Prices}

Production cost modeling is based on each unit's estimated marginal cost. Locational marginal prices that clear in the day-ahead and real-time markets are set by a similar computational procedure that is run for each operating interval except that generators submit cost-based offers to supply energy. Each "at or above" offer price tends to be the short-run marginal cost of that increment of energy provided that the market is competitive. However, if the generator can exercise market power even to a small degree, it could submit offers that are higher than the true marginal cost, or it could strategically withhold some of its capacity from the market to induce higher locational marginal prices. ${ }^{16}$ This means that the prices suggested by production cost modeling runs can be somewhat higher than the locational marginal prices in actual market outcomes.

A highly simplified example illustrates how strategic bidding can work. If a generator has 100 MW it can offer into the market, all with a marginal cost of $\$ 50 / \mathrm{MWh}$, it would offer all 100 MW into the market, the locational marginal price would clear at $\$ 60 / \mathrm{MWh}$, all of the generator's offer would be dispatched, and the generator would make $\$ 6,000$ for that interval (100 MW offered multiplied by the locational marginal prices of $\$ 60 / \mathrm{MWh}$ ). On the other hand, if the generator withholds $5 \mathrm{MW}$ from the market, the diminished supply would cause the locational marginal price to clear at $\$ 70 / \mathrm{MWh}$. In this case, the generator would earn $\$ 6,650$ (the new locational marginal price multiplied by the $95 \mathrm{MW}$ it did not withhold), which is more than it would have made had it simply offered all its capacity at marginal cost. If there is a $50 \%$ chance of success, then the risk-weighted value of withholding ( $95 \mathrm{MW}$ multiplied by a $50 \%$ chance of a $\$ 70$ locational marginal price plus $95 \mathrm{MW}$ multiplied by a $50 \%$ chance of a $\$ 60$ locational marginal price) is still higher than the $\$ 6,000$ the generator would earn by simply offering all $100 \mathrm{MW}$ at its short-run marginal cost.

\footnotetext{
${ }^{16}$ Most RTOs have price mitigation measures that apply when certain competitive indices are triggered. Strategic bidding can still occur when such indices are not triggered.
} 
Similarly, the generator could offer $5 \mathrm{MW}$ at a price higher than its marginal cost while offering the rest at its true marginal cost of $\$ 60 / \mathrm{MWh}$. If that increment were to set the $\$ 70$ locational marginal price, then the price paid for the entire $100 \mathrm{MW}$ would reflect a premium above the generator's actual marginal cost.

CAISO uses a price-cost markup regression analysis that is based on historical data to determine the potential scope of the strategic bidding. Pricing data from different periods reflect a range of strategic bidding price markups. After generating the regression equation, CAISO identifies the quantity of the unhedged load that is exposed to spot market prices.

To develop a range of potential strategic bidding scenarios, CAISO models the case in which each market participant bids at their marginal cost, a case employing the regression equation bidcost markup output, and an upper-bound scenario that reflects a scenario in which $90 \%$ of the predicted markups would be lower than the selected markup. These markups are then input into the model.

\subsubsection{Uncertainty}

Future strategic bidding is one of many points where forecasts of future conditions can be wrong. To address the uncertainties, CAISO conducts multiple scenarios of future conditions to generate a more comprehensive understanding of what the future might look like and whether a transmission upgrade may be beneficial among those scenarios. CAISO also includes sensitivity analyses that vary a particular critical input, such as natural gas prices, among the scenarios. Finally, to gauge the probability and impact of certain system outages, such as unplanned maintenance, CAISO employs a Monte Carlo analysis to evaluate the benefits of a transmission project in these instances as well.

The full CAISO methodology can test sensitivities among multiple scenarios. Each set of variables (future load growth and future natural gas prices, for example) includes the most likely condition, high and low bookends, and in-between conditions of particular interest that are identified through stakeholder consultation and user experience. These possibilities can then be arranged into a matrix. The joint probabilities of the conditions tested provide weighting factors by which the cost-benefit ratios for all outcomes may be combined. The outcomes also provide a range of expected benefits of a project that can be compared to the total cost and provide a more comprehensive outlook of the value of a given transmission upgrade in the market.

\subsubsection{Alternative Resources}

Transmission upgrades are not the only means to alleviate congestion so CAISO compares the expected benefits of a transmission upgrade to those of alternatives, such as new central station generation, alternative transmission options, and renewable generation, among others. The goal is to determine whether alternative resources can substitute for a transmission upgrade or if an upgrade improves the economic position of certain alternative resources.

For this comparison, CAISO employs a resource optimization process to determine how the system would react to a transmission upgrade. CAISO tests a range of future scenarios for possible wholesale power prices based on different levels of electricity demand and different levels of natural gas prices. 
CAISO then calculates a revenue target based on those scenarios to determine whether new generation might be a viable option. CAISO assumes that any new generation will be independent and nonstrategic in the market. The generator's offer prices are assumed to be at

levels that would maintain competitive prices while providing an adequate rate of return.

The difference in costs among these scenarios indicates the benefits of the transmission upgrade compared to alternatives. It also suggests the potential benefits associated with a transmission project as it relates to spurring new economic generation, which CAISO factors into their benefit calculation for new transmission projects.

\subsection{Regulatory Oversight}

Before requiring the use of CBA to evaluate infrastructure expansion, a regulatory agency would need to ensure that it had staff-level expertise capable of evaluating the methodologies, assumptions, and inputs used in any analysis. These staff would include economists with advanced degrees as well as engineers and operation research specialists who are familiar with the power systems modeling used to inform the CBA.

In most cases for specific projects, the CBA would be done by the developer using spreadsheet software, but any intervenor possessing the analytical capability could conduct an independent analysis. In this case, the regulator might have a set of contested issues among competing analyses on which all other stakeholders could provide comment. The role of the regulatory staff would be to review the assumptions and methodologies used in the CBA with an orientation toward the public's interest rather than the interest of the developer or any individual party. In the United States, regulatory staff seldom conduct their own CBA for a proposed project; rather, their role is to review the spreadsheets submitted by the party (or parties) who conducted the analysis.

The agency may need to conduct or participate more actively in a CBA to evaluate a major policy initiative affecting several potential projects or the wholesale market overall. Staff may conduct the analysis, or the agency may elect to retain its own economic consultant to work with staff. An example of a major policy effort is transmission to serve renewable energy zones, which could involve the economic evaluation of several possible transmission projects separately and together as choices among portfolios. 


\section{Modeling and Measuring Reliability in the Bulk Electric Power System}

Improving reliability is a typical and compelling rationale for seeking regulatory approval for new transmission assets. As discussed earlier, justification for reliability upgrades (as opposed to upgrades driven by policy or economics) may look different than a CBA and involve engineering studies. This section includes discussion of the process for modeling and measuring reliability to comply with NERC standards (or avoid future noncompliance). The section begins with a review of reliability and the role of NERC and then reviews different metrics for reliability: the value of lost load (VOLL), resource adequacy, curtailment, and losses. The section concludes with a review of modeling approaches to measure reliability.

\subsection{Overview of Reliability Standards}

Reliability is maintained by ensuring a balance among generation, transmission, and distribution infrastructure and operations. In the distribution system, the most common cause of loss of power is a localized event. To prevent these, utilities prioritize proactive measures such as trimming trees and maintaining equipment, but they are never $100 \%$ able to prevent some system losses. These losses are usually confined to small numbers of customers, although occasionally widespread outages occur such as those caused by weather events.

In the transmission system, it is infinitely costly to ensure $100 \%$ reliability because that would entail the need for endless redundancies of transmission lines, equipment, and maintenance, but the transmission and generation sectors are monitored more closely than the distribution system. Failures can occur when equipment protects itself by "tripping off" the system, and in some cases this further contributes to the instability of the system. Thus, at higher voltages and in the generation sector, because of both the large number of electricity users that may be affected and because of the high consequences of cascading failures, more efforts are undertaken to monitor and prevent system failures.

The bulk power system in the United States falls under the regulatory authority of NERC, which is overseen by FERC. NERC:

- Develops and enforces reliability standards

- Evaluates seasonal and long-term adequacy

- Monitors the power system, including maintaining an extensive database of existing and forecast system parameters

- Educates and trains industry, including utility and system operators (NERC 2015a).

NERC petitions to FERC to obtain approval of reliability standards or modify existing standards in an ongoing process as the power system expands and evolves. Many parameters measure different aspects of system reliability, and these are tracked and published by NERC. For example, to consider load loss due to generation or transmission, NERC tracks a daily Severity Risk Index, a Bulk Power System Transmission Related Events annual counter, and the number of megawatts of lost load from under-frequency load-shedding events. These are only a few of the many specific and technical indices that consider the amount of lost load or near lost load and 
the causes of the events. NERC also tracks interconnection frequency response, which measures a system's ability to stabilize the frequency after a disturbance, such as one due to a major generator outage.

Other standards that are included in operational guidelines are tracked in varying time frequencies, often in near real time. A weekly report is published and publicly available to provide transparency into the power system. NERC's set of current and approved-for-future reliability standards in the United States numbers more than 200 (see NERC [2015c]). See Table 2 for examples.

Table 2. Examples of NERC Reliability Standards

\begin{tabular}{|l|l|l|}
\hline Standard & Title & \multicolumn{2}{|l|}{ Purpose } \\
\hline BAL-001-1 & $\begin{array}{l}\text { Real Power Balancing Control } \\
\text { Performance }\end{array}$ & $\begin{array}{l}\text { To maintain interconnection steady-state frequency } \\
\text { within defined limits }\end{array}$ \\
\hline $\begin{array}{l}\text { BAL-005- } \\
0.2 b\end{array}$ & Automatic Generation Control & $\begin{array}{l}\text { To maintain the automatic generation control necessary } \\
\text { to calculate area control error and to routinely deploy } \\
\text { regulating reserve }\end{array}$ \\
\hline TPL-001-4 & $\begin{array}{l}\text { Transmission System } \\
\text { Planning Performance } \\
\text { Requirements }\end{array}$ & $\begin{array}{l}\text { To develop a bulk electric system that will operate } \\
\text { reliably over a broad spectrum of system conditions }\end{array}$ \\
\hline $\begin{array}{l}\text { MOD-001- } \\
2\end{array}$ & $\begin{array}{l}\text { Available Transmission } \\
\text { System Capability }\end{array}$ & $\begin{array}{l}\text { To disclose the methodology and data underlying } \\
\text { determinations to entities that need information for } \\
\text { reliability purposes }\end{array}$ \\
\hline
\end{tabular}

The myriad guidelines and requirements give power system participants the responsibility to contribute at a minimum level to ensure safe and uninterrupted power system operations. The numeric parameters are collated for evaluating the bulk electric system more generally, and they are considered over time frames that span current operations to long-term planning.

Many of these standards contribute to an Adequate Level of Reliability (NERC 2015b).

According to NERC, this is defined by the following bulk power system characteristics (NERC 2013):

- The system is controlled to stay within acceptable limits during normal conditions.

- The system performs acceptably after credible contingencies.

- The system limits the impact and scope of instability and cascading outages when they occur.

- The system's facilities are protected from unacceptable damage by operating within facility ratings.

- The system's integrity can be restored promptly if it is lost.

- The system has the ability to supply the aggregate electric power and energy requirements of the electricity consumers at all times and takes into account scheduled and reasonably expected unscheduled outages of system components. 
The technical document that supports this general system risk level and its mission for compliance discusses the objectives in the context of phases of steady state, transient, operator response, and system restoration. The National Renewable Energy Laboratory (NREL) understands that a grid code is being proposed that incorporates many of these characteristics and is now in the process of public consultation for approval.

\subsection{Review of Reliability Metrics}

\subsubsection{Value of Lost Load}

As mentioned above, minimizing interruptions in electric service is a goal held by power utilities, system operators, and NERC and FERC alike. When evaluating transmission expansion or improvements with a rationale based on reliability arguments, it is helpful to understand the economic costs of service interruptions or blackouts (see sidebar).

The VOLL refers to the costs associated with interruptions in electricity supply. Welle and Zwaan (2007) summarize the methods of estimation and values of VOLL from relevant studies among different

Blackouts are interruptions in power service. Brownouts are periods of poor power quality when there is a voltage reduction. These may be noticed in the lights dimming. These voltage sags can have serious detrimental consequences - for example, to factory equipment that relies on stable power. countries. Usually the VOLL is based on the damages associated with the power supply shortage, and it is calculated as the ratio between the estimated total damage caused by not-delivered electricity over the amount of electricity not delivered.

For example, disruptions created by production failures (e.g., incorrect market signals, the interruption of other production capacity or shortage of reserve capacity) or by network failures have different associated consequences. Production failures usually create electricity price peaks that amore adversely affect customers that have real-time metering (e.g., some industrial customers) than customers that have an average metering rate (e.g., residential customers). For instance, customers facing high electricity rates will disconnect when their marginal costs surpass the value of their marginal production. Network failures are usually not accompanied by abrupt price changes because in a network failure both demand and supply are disrupted, and as such electricity costs are not differentiated between real-time metered and other types of rates.

\subsubsection{Methodology to Estimate VOLL}

The VOLL varies by customer type (industrial, residential, commercial), expectations for reliability (high/low willingness to pay), time of occurrence (season, day of week, time of day), duration (long interruptions might have a diminishing associated marginal cost), and notification of occurrence (due to potential preventive actions that reduce the costs) (Welle and Zwaan 2007).

The following four categories summarize different ways to estimate the damages associated with a power shortage (Welle and Zwaan 2007):

1. Revealed preferences refer to the additional investments consumers make to avoid a blackout—e.g., storage or backup power contracts. The expected gain from a marginal 
unit of electricity self-generated by backup power has to be at least equal to the expected marginal loss due to the electricity not supplied. Thus, the marginal costs of selfgenerating electricity are an estimate for marginal interruption costs (Ajodhia 2006).

2. Stated preference surveys ask for the willingness to pay for more reliability and the amount one is willing to accept for less reliability. These values are assessed under different combinations of scenarios to create a utility function to reach a VOLL estimate.

3. Proxy methods inspect variables related to the direct costs induced by power supply interruptions - e.g., costs of lost production, costs associated with restarting machinery, inconvenience costs of lost leisure time, spoiled goods, and stress. Quantifying costs for households is more complex because they do not produce goods. For instance, the market value of leisure time can be approximated to the wage rate (because people increase their working time until the value of labor is less than the marginal value of leisure). In general, an upper bound of economy-wide average interruption costs is the ratio between gross domestic product to electricity consumed in the economy.

4. Case studies gather data from different power disturbance events.

\subsubsection{International VOLL Estimates}

Recent studies refer to VOLL estimates as high as $\$ 77 / \mathrm{kWh}$ (New Zealand). In the United States, ERCOT's VOLL estimates vary from $\$ 0.11 / \mathrm{kWh}$ to $\$ 7 / \mathrm{kWh}$ for residential and industrial customers, respectively (Ela et. al 2014). Midcontinent Independent System Operator's small commercial/industrial consumers have VOLL values of $\$ 42 / \mathrm{kWh}$ (London Economics 2013). For comparison, in the former regulatory framework in Mexico, Comisión Federal de Electricidad (CFE) used $\$ 1.50 / \mathrm{kWh}$ as a reference value for energy not served. NREL understands that CRE has proposed to maintain this value in the grid code until the Secretaría de Energía (SENER) establishes a different one.

Welle and Zwaan (2007) estimate a VOLL in the range of $\$ 4 / \mathrm{kWh}-\$ 40 / \mathrm{kWh}$ for developed countries and $\$ 1 / \mathrm{kWh}-\$ 10 / \mathrm{kWh}$ for developing countries (2004 values). With a $90 \%$ confidence level, they narrow the values to $\$ 5 / \mathrm{kWh}-\$ 25 / \mathrm{kWh}$ and $\$ 2 \mathrm{kWh}-\$ 5 / \mathrm{kWh}$ (2004 values). See Figure 8 .

For the period from 2001 to 2008, Leahy and Tol (2011) estimate for Ireland a range between $€ 4 / \mathrm{kWh}-€ 28 / \mathrm{kWh}$ among industry, services and the residential sector (2007 values). In Germany, Praktiknjo, Hähnel, and Erdmann (2011) assess VOLL in the ranges of $€ 6 / \mathrm{kWh}-$ $€ 16 / \mathrm{kWh}$ (2007 values), with the public administration, agriculture, and industry sectors in the low end and commerce, service, and transportation consumers in the higher end.

In the United States, LaCommare and Eto (2006) differentiate total costs throughout the U.S. economy by length of interruption and customer type, and they establish a base-case estimate of $\$ 79$ billion per year (2002 value) due to power interruptions. The commercial sector bears $72 \%$ of this share, industry $26 \%$, and the residential sector the remaining $2 \%$. Two-thirds of the total costs are estimated to be due to momentary interruptions, and one-third is due to sustained interruptions.

It is worth noting that, rather than VOLL, ancillary service scarcity prices are more frequently used to determine prices during scarcity because in typical power system operations shortages 
will first result in insufficient reserve while load remains served (Ela et al. 2014b). In this way, VOLL is being implicitly incorporated into the ancillary service pricing of reserve capacity.

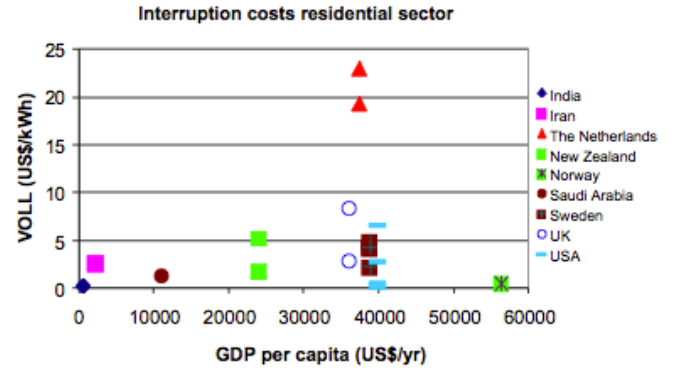

(a)

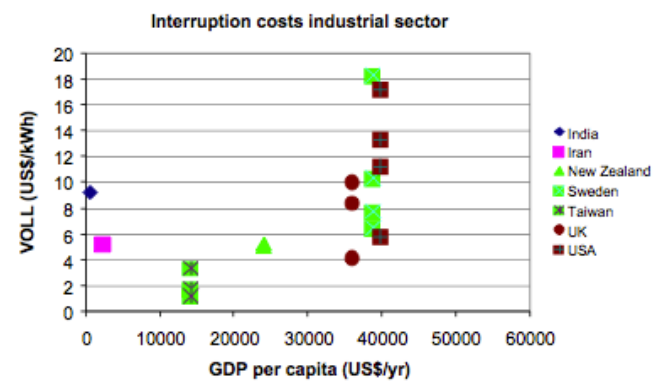

(c)

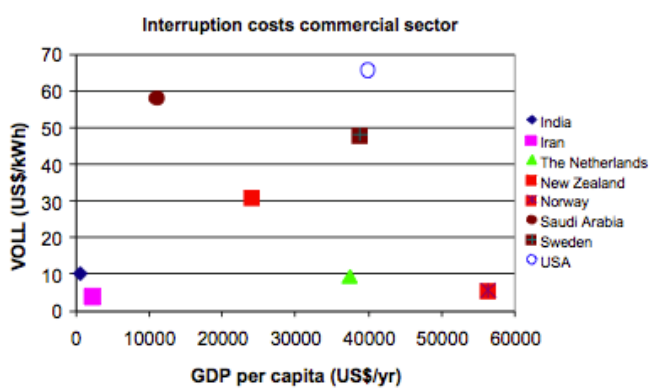

(b)

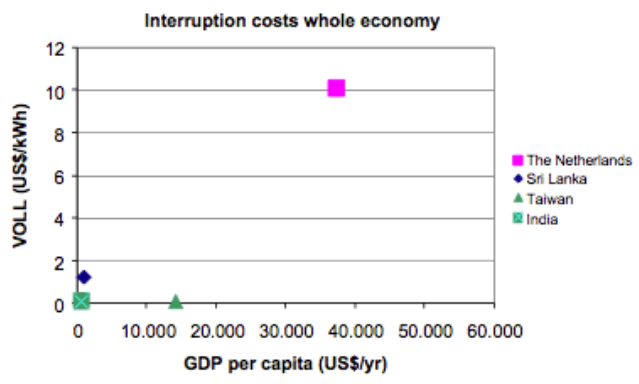

(d)

Figure 8. Comparison of VOLL among sectors and countries. Image from Welle and Zwaan (2007)

\subsubsection{Resource Adequacy}

In addition to transmission reliability, the main area of concern for regulators with respect to power reliability generally has to do with ensuring that enough generation resources are on the system now and in the future.

\subsubsection{Planning Reserve Margin}

System adequacy includes ensuring that there is enough generation supply to meet demand. Considering unplanned equipment outages, reliability calls for a surplus of generation capacity over peak demand. Traditionally, utilities planned for a margin of generation reserves over the projected peak load demand in a given year. The amount of generation capacity reserves to be required is obtained by first determining the loss of load probability to target. Other related metrics are derived from that number, and they all represent the risk tolerance for power outages.

For example, the loss of load expectation might be set at a typical target value of 1 day in 10 years, which reflects the risk of power interruption. There are other similar metrics, such as loss of load hours and expected unserved energy. Whereas loss of load expectation and loss of load hours calculate the number of power interruptions, expected unserved energy captures the magnitude of the shortfall because it is measured in MW or MWh instead of a discrete number of power interruptions. At times these metrics are used inaccurately because they refer only to a system's internal demand and supply and do not always refer to the ability to share reserves among systems or balancing authority area boundaries. 
Computing this planning reserve margin becomes even more complex when considering a large contribution from renewable resources that are variable and uncertain. System planning is dependent on aggregate capacity values.

One measure of aggregate capacity value is the effective load-carrying capacity, which is the contribution that each generator makes to resource adequacy, also known as the generator's capacity value. For traditional generators, this value is based on assumed forced outage rates. For renewable generators, it is based on assumed resource availability. When generation is added to the system, the loss-of-load expectation is reduced. Alternately, new generation can be viewed as how much more load can be served at the same risk level, i.e., holding the loss-of-load expectation constant.

See Figure 9 for an example of how an additional 400-MW load can be served by adding an unnamed amount of wind capacity. This same method can be applied to the addition of transmission lines to determine either how much more load can be served or how much reduction in load loss can be expected. Just as for generation resources, to use this capacity value algorithm, which can be implemented using a planning model or economic dispatch model, outage rates must be assumed for transmission lines. ${ }^{17}$ Transmission outage rates may be determined stochastically and probabilistically, or heuristically and historically.

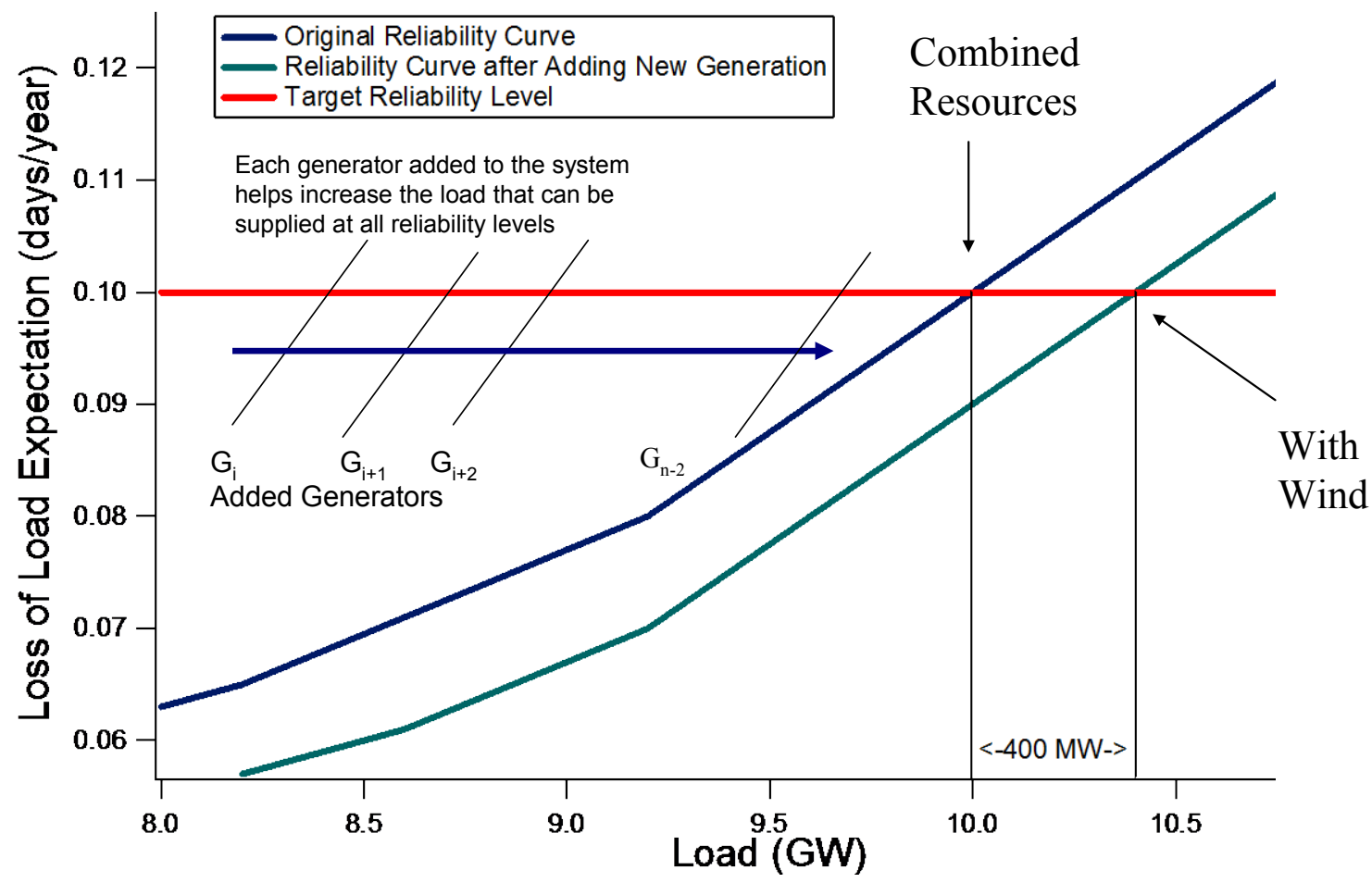

Figure 9. Load that can be served before and after new wind. Image from Milligan (2011)

\footnotetext{
${ }^{17}$ Similarly, transmission outage rates must be assumed for planning models and unit commitment/economic dispatch models, and they can be derived using various methods. Load flow models more accurately reflect losses based on explicit line impedance values and other parameters.
} 
There are many ways in practice to determine how much capacity value can be attributed to renewable resources, and the choice of metric (loss-of-load expectation, loss-of-load hours, or expected unserved energy), is not dependent on the underlying types of generating assets (Ibanez, E., and M. Milligan 2014). NREL understands that in 2009, CRE issued a methodology to measure the capacity credit for renewables. This methodology was intended to be used by CFE for planning purposes. After studying the Equivalent Firm Capacity concept, CRE's recommended methodology was based on effective load-carrying capacity and loss-of-load probability parameters and may be reconsidered in the context of the Energy Transition Act.

\subsubsection{Operating Reserves}

Operating reserves are a subset of resource adequacy and another area of focus to ensure reliability on the system. With increasing levels of variable generation and its uncertainty, operating reserves are one of the components of flexibility.

\subsection{Flexibility}

Flexibility is the ability of a system to respond to changes caused by variability and uncertainty in demand and supply (Milligan et al. 2015). Loads change, sometimes in unpredictable ways, and conventional generators can fail unexpectedly. Variable generation, such as wind and solar power, contribute additional variability and uncertainty because their available power changes through time based on changing weather patterns, and this available power cannot be perfectly predicted at all time horizons.

The need for flexibility applies to all timescales, ranging from the many years that comprise the planning and investment time horizon, to operational planning that may involve days to months, and to operations itself, which encompasses periods as long as a few days to as short as subseconds. The shortest time intervals are those in which inertial/frequency response provides the first line of defense against imbalance or frequency excursions. Note that wind turbines and solar inverters can now provide simulated inertial response and frequency response along with automatic generation control, and they can even respond to dispatch signals. Therefore, wind and solar power are capable of providing some of the additional flexibility needs that they induce; however, these may not always be the most economic source of this flexibility.

\subsection{Reliability}

A reliability focus should consider whether the amount of resources on a system is adequate to provide reserves. These operating reserves include day-to-day resources (steady state) and those needed for disturbance response (dynamic). Below is an illustration of the increased regulation needs for a system with wind power. The top curve shows in blue net load (load minus wind). The bottom graph shows the additional up and down ramps needed to account for the wind. 

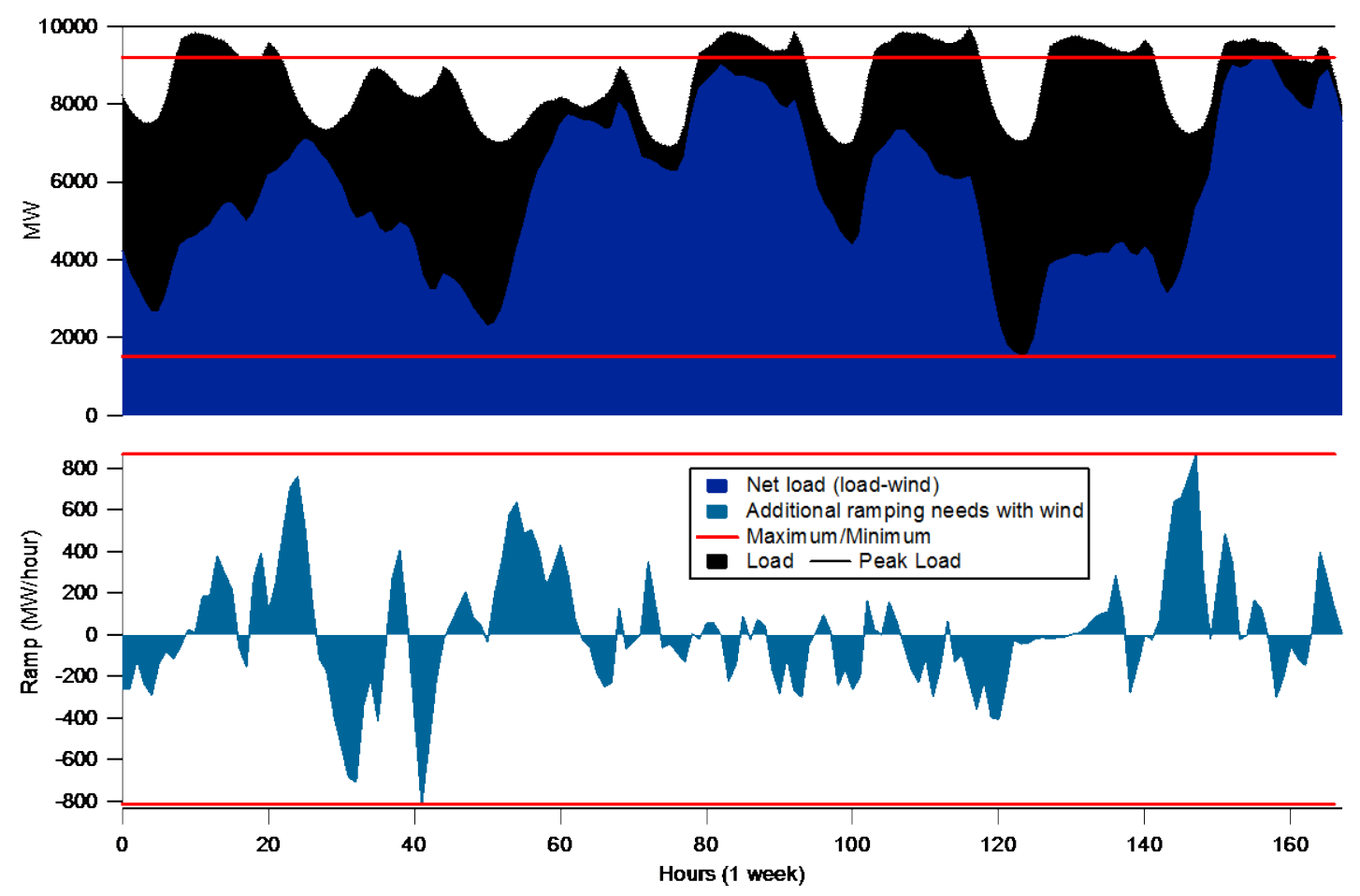

Figure 10. Additional ramping needs for a flexible system

The regulation requirement to match supply and demand on a minute-to-minute basis is provided by operating reserves. Traditionally, these reserves are thermal units such as simple-cycle combustion turbines operating on automatic generation control. However, with increased variable generation and the availability of sophisticated power control electronics, wind and solar resources can contribute to regulation services with the right incentives or interconnection requirements. Other options worth noting are creating a designation for intermittent resources to contribute to the portfolio that the operator uses to match demand and supply. Examples of this are Midcontinent Independent System Operator's Dispatchable Intermittent Resource category and Independent System Operator New England's proposal to send Do Not Exceed Dispatch Points for wind generators above $5 \mathrm{MW}$ on its system to better manage local congestion and avoid curtailment (FERC 2015). Xcel Energy is using active power control capabilities of wind to regulate frequency on its system in Colorado.

Regulating reserves are only one type of reserve that is changing with the evolving power systems. Many reserve classifications have definitions that vary based on specific power systems. Following reserves are provided from spinning units and can take on the order of 10 minutes to respond to ramps steeper and greater than a normal net load event. An unforecasted weather system is a sample cause of the need for manually

Grid services are available from inverter-based renewable energy generators with fast-responding power electronics. Wind can provide inertial response based on the kinetic energy in its rotor. Wind and solar can provide fast frequency response, primary frequency response, and regulating up and down services through automatic generation control. NREL has done work on both wind (Ela et al. 2014a) and solar (Gevorgian and O’Neill 2016). 
calling on following reserves. Other reserves are held in case a discrete event on the power system generates a supply-demand imbalance, such as a problem on the transmission system or with a generator. The frequency of the grid outside of a deadband can provide the signal for units to automatically provide these reserves. Frequency or frequency deviation from nominal can generally be used as a reliability metric to provide information about the health of the grid. Disturbance response to contingency events is discussed in more detail in Section 3.3.3.

\subsubsection{Curtailment}

Curtailment occurs when renewable energy generating units are asked to turn down or off. Curtailed energy, also called dump energy, has two main causes. The first is economics (and the physical characteristics of other generation), and the second is transmission capacity. The former can be used to help evaluate benefits associated with a transmission project. The latter is another indicator of reliability in a power system.

Economic curtailment occurs during certain dispatch stack conditions. Resources are dispatched in order of least cost with some exceptions due to operating constraints or contractual provisions. For example, take-or-pay contracts may create a must-run status for economic reasons or proprietary bilateral contract obligations. Another example is physical whereby some thermal units must run at a minimum turndown generation level or are constrained by ramp limits. The level is derived from the perceived damage or wear and tear on components to cool down and heat up again in addition to its accompanying the surge in heat rate and additional fuel requirement. The first example can be remedied contractually, but the second is harder to remedy in the short term. Otherwise, theoretically, units should be dispatched based on their marginal cost of operation. This would have wind, solar, and hydro at the bottom of the dispatch stack, following the must-run units. However, at times of low load and high renewable generation-e.g., wind at night - to avoid violating the must-run status of those units, renewables may be curtailed.

A history of system practices not designed to accommodate variable generation and reward players for being flexible reflects poor institutional frameworks that should be restructured in the changing environment. See Ela et al. (2014b).

Lack of transmission capacity occurs when conditions on the power system indicate a need to modify power flow to maintain reliability including acceptable voltage and frequency levels. Many parameters determine the health and condition of the power system status. Operators monitor system conditions and run power flow models continually to ensure that constraints are not being violated. If so, possible system modifications can be made to ensure balance and stability. If other measures are not successful, generating units may be asked to lower their output levels or cease operating lest they be forced to curtail through a breaker trip. These operator-ordered curtailments are harder on the generators' substation equipment than a controlled reduction. A controlled reduction often arises when there are few good options for interconnection and a flood of new wind or solar development threatens to overload a vulnerable point on the grid.

However, whether new transmission is the right solution depends on many factors. As in the United States, Mexico's regulators could be called on to decide the merits of congestion-related transmission projects. The right answer will often rely on more than a power flow analysis; it 
could involve judgments about long-term strategies and the public interest. For example, regulators may need to decide between building new transmission that would eliminate curtailment and allowing curtailments to persist to provide an economic signal for development to take place elsewhere on the system.

U.S. experience with renewable energy curtailment has evolved during the last two decades in conjunction with advances in wind and solar technology, improvements in forecasting, and the development of organized wholesale power markets. (For a comprehensive overview of recent U.S. experience with renewable energy curtailment, see Bird, Cochran, and Wang [2014]). As a result, wind curtailments have been decreasing even as the total amount of wind power in service has increased.

In markets such as ERCOT, operator-instructed curtailment to resolve local line congestion has largely been replaced by nodal pricing and full economic dispatch. Offer prices submitted by managers of renewable energy projects are the basis for deciding which generators are deployed and which are not when transmission capacity at a given point is constrained. The locational marginal prices that come from ERCOT's economic dispatch software provide price signals for where to site new renewable development, and they provide data for more precisely evaluating the costs and benefits of a new transmission line.

With nodal pricing and economic dispatch substantially resolving curtailment due to transmission constraints, the role of the regulator in transmission planning tends to shift away from resolving curtailment and other isolated local issues one at a time and toward long-term strategic planning. California regulators, for example, launched a statewide Renewable Energy Transmission Initiative that studied options for opening up new areas for renewable energy development. The objective was to identify renewable resource areas and transmission options that were cost-effective by taking into account environmental and other land use concerns. The knowledge base and analytical tools developed as part of this effort are still used by regulators to evaluate the merits of new transmission projects.

Another example of regulators shifting to long-term, system-wide transmission planning is the Texas CREZ initiative, described earlier in Chapter 2. By the time CREZ lines were energized, economic dispatch had been fully implemented and was resolving most local congestion without the need for regulators to approve specific new lines. Instead, the CREZ lines served a larger objective that went far beyond curtailment: siting new large-scale wind generation in areas where the production per dollar invested would be lowest. Curtailments were reduced as a side effect because the geographic diversity enabled by the CREZ lines helped prevent overloading new wind power at electrically vulnerable points on the grid.

\subsubsection{Losses}

Losses are another key parameter to consider when assessing the reliability of the electric system. A DC power flow simulation is required to estimate transmission losses. When regulators evaluate a request for transmission upgrades, they may perform an optimal power flow analysis to see how the losses parameter is affected by the upgrade. 


\subsection{Modeling to Assess Reliability}

In all power system evaluations, modeling is used to simulate existing or hypothetical conditions. The depth and breadth of models are enormous, spanning from microsecond views of each phase of voltage waveforms to decades-out, capacity expansion planning models. To evaluate the PRODESEN, three generic categories of models are typically considered: capacity or transmission expansion planning, unit commitment and economic dispatch, and power flow or contingency planning. Very few models are good at performing more than one of these roles, even if they are technically capable of doing so. The right tool is key to accurate results and correct interpretations. Model examples generally include off-the-shelf commercial models and custom-built proprietary models, some of which have organically grown over the years through an organization's evolving needs. From the regulatory perspective, these models should invoke confidence both for their algorithms and appropriateness as well as their robust input data and assumptions.

In most regulatory agencies, staff do not run these detailed models for all decisions pertaining to infrastructure investment approvals. Rather, the regulatory staff should develop sufficient expertise and familiarity with the model to be able to check the work performed by the applicant. The regulatory staff review in detail how the model was set up, its input assumptions, and the output, which is a less extreme version of an audit. However, for big projects and large sums of capital dollars at stake, regulatory staff are more likely to attempt to mimic the model's results by explicitly running the model that the developer used to create the rationale. In this case, it is helpful to have either engineering staff or at least very analytical staff available to build the case and evaluate the scenarios. See Section 5.1 for more information about staff skill sets.

\subsubsection{Capacity or Transmission Expansion Planning}

Planning models are designed to evaluate least-cost (capital and operations) capacity expansion subject to policy and modeling constraints. The models typically run on medium- to long-term planning horizons (e.g., 20-50 years) and require good data on all loads and resources, including renewable energy resource availability, capital costs, and fuel prices, among other inputs.

To study the power sector over such a long time frame, the models evaluate a sample of specific time periods each year that reflect representative conditions. The models have a detailed load forecast and choose dispatch and expansion needs from among both existing units and future generic generation resources (with built-in assumptions about technology cost and performance). The transmission system is generally represented in planning models with a "pipe and bubble" approach. This means that balancing authority areas are connected to neighboring balancing authority areas with a "transport" representation wherein power moves from source to sink along a "route" or "pipe" between areas and intra-area congestion (in the "bubble" of the load/resource area) is ignored. In reality, power flow on any given transmission line affects all flows in the network inversely proportional to the impedance of the lines. Because modeling power flow accurately is so complex, many planning tools use the transport simplification.

The models have a detailed cost-computation capability that includes the following factors:

- Capital costs

- Return on investment 
- Cost of money

- Variable and fixed operations and maintenance costs

- Fuel costs.

A capacity expansion model can run a multitude (sometimes thousands) of scenarios to determine the optimal set of resources based on lowest cost subject to constraints identified by policy targets, operational limitations, high resource areas, etc. Some entities develop this capability in-house by starting with a spreadsheet model and ultimately incorporating complex logic through macros and Visual Basic commands.

An example of this type of model that is commercially available is Strategist, which is produced by Ventyx, an ABB company. Examples of noncommercial models of this type are two that NREL developed for its own capacity expansion studies. The first is called the Regional Energy Deployment System (ReEDS), which models 17 times slices, 134 balancing authority areas, and 356 renewable energy resource regions throughout the United States. ReEDS has an NRELdeveloped annex model called USREP that allows ReEDS to go beyond asset-based cost computations and produce results for the economy including changes in prices such as labor and goods, economic output by industry and sector, gross domestic product, and income and welfare by class.

The second NREL capacity expansion model is called the Resource Planning Model (RPM), which goes into much greater detail than ReEDS and is used for examining a balancing authority area or subregion more closely (such as details at the unit level instead of plant level) while representing external balancing authority areas in an aggregate manner for interchange possibilities. See Figure 11 below.

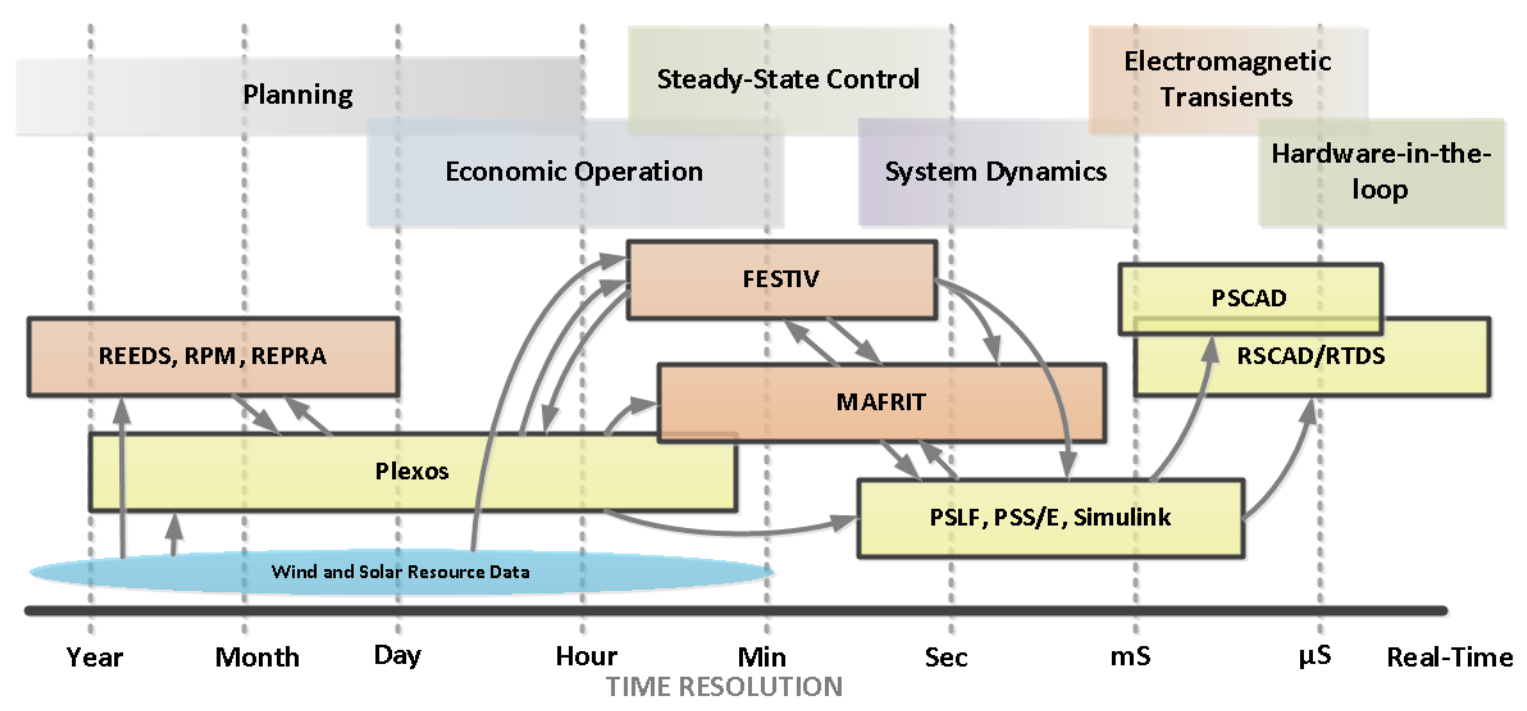

Figure 11. NREL's in-house and commercial power system modeling tools

\subsubsection{Security-Constrained Economic Dispatch}

A security-constrained economic dispatch model, also called a production cost model and unit commitment and economic dispatch model, simulates power system operations subject to 
physical and economic constraints. The model can be used to evaluate the operational feasibility and relative costs of future scenarios (e.g., impacts of renewable energy growth, impacts of regulatory actions to improve system flexibility). Unlike a capacity expansion model, securityconstrained economic dispatch models are run at hourly or sub-hourly intervals during the course of a year. This type of model requires detailed information about generation characteristics and time-synchronous data on renewable energy and load among other considerations.

The basic configuration has the minimization of system cost as its objective function subject to constraints. The model may optimize more than one objective function, such as the minimization of emissions, if specified. However, even without dual objective functions, the model is inherently nonlinear; it uses Lagrangean multipliers to derive the optimal solution. To make it feasible to solve, a Lagrangean relaxation approach is used to represent the problem as a DC power flow, linearized model. Security constraints typically refer to transmission capacity limitations in the model's representation.

These production models require considerable data to accurately represent constraints on the power system. For generating units, these include the following, among others:

- Minimum and maximum generation levels

- Ramp-up or ramp-down limitations

- Heat-rate curves (fuel burned depending on level loaded)

- Start-up time after being down for different time periods (hot start, warm start, cold start)

- Fuel cost

- Carbon dioxide, nitrous oxides, sulfur dioxide, particulate matter emissions, etc.

The models are run at hourly or sub-hourly (15-minute or 5-minute) increments with the units' status setting the starting conditions for the next modeled state. To do so requires load forecasts at the same time step. This is usually based on some assumptions about history repeating itself. Modeling load accurately will become increasingly more important as distributed generation, demand response, and the use of smart devices becomes more widespread.

Security-constrained economic dispatch models have varying levels of specificity in their representations of the transmission system. Sources and sinks for power can be physical electrical buses at substations in the system (nodal) or aggregations of load demand and generation supply at notational locations (zonal). The solve time required for optimization modeling is directly impacted by the level of detail of the transmission representation. Optimal power flow means that the model must compute all possibilities of transmission path flow to determine which choice has more impact on the model's objective function, usually to minimize system costs. In practice, depending on system size and due to solve time practicality, it may be necessary to heuristically run a partial time step to observe which transmission constraints are binding and then only enforce the ones that indicate possible congestion.

Similarly, because the volume of data and computational needs are high, running an hourly or sub-hourly dispatch model is rarely performed for more than one year of simulation. For some 
needs, it is sufficient to choose representative weeks of a year, as is done in capacity expansion modeling.

Detailed system operation logs are especially suitable for assessing anticipated system reliability because they include unit output, locational marginal prices, emissions, transmission losses, curtailment, and resource adequacy.

Commercially available security-constrained economic dispatch models include PLEXOS, ProMod, UPLAN, and GridView. See Table 3 for examples of power system models used in the United States.

\subsubsection{Power Flow and Contingency Planning}

Power flow modeling, also called load flow modeling, assesses technical feasibility and reliability impacts at shorter time horizons (e.g., less than 5 seconds). A contingency on the system (e.g., a line going down or a generator tripping off) causes a fault or a disturbance that needs to be remedied. Disturbance response, and generally transmission system dynamic stability (both frequency and voltage), is a large part of reliability assurance, and it happens in that shorter time frame.

Power flow models can be used to simulate real and reactive power flow, voltage stability, fault tolerance, and contingency response, and they are conducted for a specific set of time periods, such as time periods correlating to system stress. Unlike production cost models, power flow models consider the alternatingcurrent aspects of electricity, including voltage and voltage phase angle at each electrical bus plus real power and reactive power flow along each line. Power flow models are designed to view these parameters in both steady-state and dynamic conditions. Commonly used examples of this type of model include Positive Sequence Load Flow (PSLF) and Power Sequence Simulation for Engineers (PSS/E). See Table 2 for more.

A significant output variable of load flow models used in assessing reliability is the power system losses parameter. This is an indicator both of reliability and economic efficiency because

Distribution-level changes can impact transmission-level events. A high penetration of distributed generation can impact cascading failure. For example, coordinated tripping of rooftop photovoltaic can contribute to a contingency event. Power flow modeling and appropriate grid codes are important in this changing environment.
NREL has been involved in some key work regarding both system frequency and voltage stability with high penetrations of inverterbased generation. See Miller et al. (2014) and Miller et al. (2015).

models are more commonly used on large systems to look at portfolios of transmission expansion projects or for contingency planning. 
Contingency planning is used for reliability assurance when evaluating power system flow. N-1 contingency planning is required for many systems in the United States; $N-1$ denotes the removal of the most critical key element, such as a transmission line, to see how power flow would be altered (and if neighboring lines would be overloaded). N-1 is used to prevent cascading outages in the event of a transmission system disturbance. Sometimes N-2 is considered for even greater reliability assurance (see NERC standard TPL-001-1), wherein the two most critical elements are disabled to see how power flow is impacted. System operators conduct this type of reliability modeling, and in some places developers or incumbent generating unit owners are required to conduct (or pay for) a contingency analysis as part of their interconnection request for new service and the resultant system impact study. ${ }^{18}$

The next level of power modeling, which is not covered in this document, considers another view of disturbance response: that at a transient timescale (e.g., microseconds, faster than a dynamic timescale) by simulating voltage on a phase-by-phase basis. Power System Computer Aided Design (PSCAD) is perhaps the widest known example of a three-phase dynamic model. It is infeasible to do this level of detailed fault modeling for a system; rather, the models are used to evaluate the local response of power system elements - for example, when evaluating the possibility of a new interconnection.

\footnotetext{
${ }^{18}$ The three basic steps of the interconnection process are feasibility studies, system impact studies, and facility studies.
} 
Table 3. Sample of Power System Models in use in North America

\begin{tabular}{|c|c|c|c|c|}
\hline Type & Name & Developer & Commercial? & $\underline{\text { User }}$ \\
\hline dispatch & PLEXOS & Energy Exemplar & yes & NREL, MISO, CAISO \\
\hline dispatch & ProMod IV & Ventyx & yes & Manitoba Hydro, MISO, PJM, \\
\hline dispatch & UPLAN & LCG & yes & ERCOT, EIA, EPRI \\
\hline dispatch & GridView & ABB & yes & WECC \\
\hline dispatch & MAPS & GE & yes & ISO-NE, NYISO, ICF \\
\hline planning & Strategist & Ventyx & yes & $\begin{array}{l}\text { Xcel, Atlantic Canadian } \\
\text { Utilities }\end{array}$ \\
\hline planning & MARS & GE & yes & NYISO, ISO-NE, MISO \\
\hline planning & MarketPower & Ventyx & yes & NERA \\
\hline planning & EGEAS & EPRI & EPRI license & $\begin{array}{l}\text { MISO, WPL, IPL, WE, WPS, } \\
\text { MGE, FPL, MDU, SMMPA }\end{array}$ \\
\hline power flow & PSSE & Siemens & yes & $\begin{array}{l}\text { NREL, Xcel, Colorado PUC, } \\
\text { NYISO, AECl, AESO }\end{array}$ \\
\hline power flow & PSLF & GE & yes & $\begin{array}{l}\text { NREL, NYISO, CAISO* }{ }^{*} \text { PG\&E* } \\
\text { AESO, SMUD }\end{array}$ \\
\hline power flow & PowerWorld & PowerWorld & yes & NERC \\
\hline dispatch & FESTIV & NREL & no & NREL, ERCOT \\
\hline planning & ReEDS & NREL & no & NREL \\
\hline planning & RPM & NREL & no & NREL \\
\hline \multicolumn{4}{|c|}{ *Models required these models for interconnection requests } & \\
\hline
\end{tabular}




\section{Case Study: Regulatory Evaluation of Direct Current Intertie between Mexico and the Electric Reliability Council of Texas}

Three DC interties exist between the CFE grid in northern Mexico and ERCOT:

- $\quad$ Reynosa-McAllen, 300-MW back-to-back high-voltage DC converter, online in 2010 (Mickey 2014; ETT 2015)

- Nuevo Laredo-Laredo, 100-MW variable-frequency transformer, online in 2007

- Piedras Negras-Eagle Pass, 30-MW back-to-back high-voltage DC converter, online in 2007. ${ }^{19}$

As with other ERCOT interconnection projects, construction cannot begin until the PUCT issues a CCN to the applicant. The PUCT may grant a $\mathrm{CCN}$ if it determines that a utility has demonstrated that the project is "necessary for the service, accommodation, convenience, or safety of the public," as stipulated by state law (PURA 1997). To make this decision, the PUCT requires the applicant to produce historic and future load projections to show that the project is necessary and sufficient to meet load (PUCT 2003). If need can be shown, the applicant must also evaluate the potential for alternative projects to satisfy that need.

A project known as the Railroad DC Tie was proposed in 2003 by Sharyland Utilities, an investor-owned utility serving the Lower Rio Grande Valley north of the river. Sharyland requested a CCN from the PUCT to build a new 138-kV high-voltage DC transmission line in the region to accommodate nearby load growth. In its filing, Sharyland forecasted that it would be expected to serve 12,000 customers with a combined load of $350 \mathrm{MW}$ (PUCT 2003). The utility anticipated a strain on the transmission network within the Lower Rio Grande Valley, which was already experiencing high load growth, substantial congestion costs, and the cost of retaining an old generator as a reliability must-run unit.

These congestion and reliability concerns were attributed to an inadequate $138-\mathrm{kV}$ transmission system in the region. Sharyland argued that these issues were expected to continue until at least 2010, when ERCOT's 345-kV transmission system would be extended farther south. Thus, a more near-term solution was necessary to resolve reliability needs (PUCT 2003). The proposed DC tie would satisfy reliability requirements by adding additional reactive power capability, opening access to $150 \mathrm{MW}$ of fast-responding power generation, and offering black-start capability (PUCT 2005).

In addition to these reliability benefits, Sharyland identified that the proposed transmission project would have wholesale price benefits for ERCOT customers (PUCT 2003). The utility said that excess natural gas combined-cycle capacity was available in northern Mexico on the

\footnotetext{
${ }^{19}$ The first interconnection between these two grids is at Eagle Pass, but it has only a 36-MW rating, and it is used exclusively for emergency backup power support. See:

http://www.ercot.com/content/meetings/wms/keydocs/2007/0515/05. DC Tie Reservation_\&_Scheduling_with_M exico.ppt; http://www.abb.com/cawp/seitp202/8192dccad527af33c125737f002b2176.aspx; and http://interchange.puc.texas.gov/WebApp/Interchange/application/dbapps/filings/pgSearch_Results.asp?TXT_CNT $\mathrm{R} \_\mathrm{NO}=28834 \& \mathrm{TXT}$ ITEM_NO=2.
} 
CFE grid. The proposed open-access transmission project would allow this generation to compete in the ERCOT market on an as-needed basis. Sharyland argued that this development would benefit customers through increased competition within the ERCOT market resulting in lower electricity costs (PUCT 2005).

Sharyland argued that alternative options - such as distribution, upgrading voltage, or adding transforms or distributed generation - would not offer benefits comparable to those of the proposed project. For example, Sharyland noted that a distribution solution might resolve the reliability issues, but it would be very costly and inefficient given both the location of Sharyland Plantation on the periphery of the ERCOT system and the load requirement. In addition, this solution and the other alternatives would not offer the wholesale market benefits associated with developing the interconnection between the CFE and ERCOT grids.

The PUCT concurred with Sharyland that a reliability need existed and that the proposed project would benefit consumers through lower energy costs. ${ }^{20}$ In this regard, the PUCT noted that during seven months out of the year, including the peak summer period, CFE's natural gas combined-cycle turbines near the border had lower marginal production costs than ERCOT (PUCT 2005). The development of the interconnection would allow these lower-cost generators to participate in the ERCOT market, whereas ERCOT generators could then sell their power to CFE during the remaining five months. According to the PUCT, this dynamic would enhance wholesale electricity market competition and lower energy prices.

\footnotetext{
${ }^{20}$ This is also consistent with a 2000 PUCT task force finding that developing open-access interconnections between ERCOT and CFE would incentivize more competition including one in the region served by Sharyland Utilities. See Project No. 20948:

http://interchange.puc.texas.gov/WebApp/Interchange/application/dbapps/filings/pgSearch_Results.asp?TXT_CNT $\underline{\mathrm{R}} \mathrm{NO}=20948 \& \mathrm{TXT}$ ITEM_NO$=19$.
} 


\section{Possible Next Steps}

CRE asked NREL to provide information about transmission planning and justifications for transmission investment based on a review of other jurisdictions. NREL reviewed aspects of California, Texas, and Colorado's regulatory processes for approving transmission projects. Those processes vary, but they have commonalities in classifications of requests based on economics, reliability, and policy. CRE should encourage the Centro Nacional de Control de Energía (CENACE) to incorporate the same designations to allow for implementations of varying criteria. NREL can evaluate the PRODESEN in 2016 to help determine if a rigorous methodology was utilized for the general assertion of the requested upgrade as the right choice and the benefits outweighing costs. Other next steps will be discussed in the following sections.

\subsection{Transmission Planning Evaluation Skill Sets}

CRE requested information about skill sets that regulators should hold in-house or on a consultant basis. This section provides more information about designations that are desirable for staff to have who monitor these complicated processes, compiled from interviews with regulatory staff. ${ }^{21}$

CRE will most likely need the technical capability to evaluate complex economic data independently to judge which projects are consistent with the public interest. Many staff responsibilities are consistent among various types of regulatory structures, and this will determine the skill sets CRE will ultimately need. In general, regulatory staff has a role in developing assumptions that underpin the technical modeling performed by the transmission system operator. They also participate in vetting the conclusions of these modeling efforts, and they participate in potentially contentious public hearings as expert witnesses. Once the proposed expansion has been vetted, the public utility commission staff must then review the actual transmission pathway for the proposed expansion. This evaluation typically centers on the transmission plan's compliance with criteria such as environmental and safety requirements, but in many states a robust public hearing process is also required before the transmission expansion can ultimately be approved.

These same staff skills will be necessary for CRE to participate in potential discussions about international reliability and operations with their regulatory counterparts in the United States and Central America. Because their responsibilities are diverse, public utility commissions require individuals on staff who have a range of educational backgrounds and skill sets. These skill sets can be broadly divided into two categories: technical skills, such as power system engineering; and soft skills, such as conflict resolution and composure under cross-examination.

The primary technical background that commission staff will need is in electrical engineering with an emphasis in power systems. An understanding of the grid's physical operation is essential to evaluate modeling results provided by the transmission system operator, participate meaningfully in transmission expansion discussions, and write and defend expert testimony.

\footnotetext{
${ }^{21}$ Personal communications between Doug Gagne and, respectively, Keith Mathis, engineering specialist from PUCT, on December 17, 2015; Jeff Billo, transmission planning manager from ERCOT, on December 29, 2015; and Robert Strauss, generation and transmission planning supervisor from CPUC; and between Barbara O'Neill and Paul Calgara, engineer in the Energy Section of PUC, on November 24, 2015.
} 
Individuals from other educational disciplines with a strong background in quantitative analysis (e.g., physics, other engineering disciplines) can also develop sufficient expertise.

In addition to expansion planning models, the two types of models that are most commonly evaluated are production cost models and power flow models. The actual evaluation of these models includes vetting assumptions, verifying results, and conducting additional CBAs of potential alternatives based on the modeling results. Other skill sets that would positively supplement electric system modelers are detailed below.

Table 4. Recommended Transmission Planning Evaluation Skill Sets

\begin{tabular}{|l|l|}
\hline \multicolumn{2}{|c|}{ Valuable Technical Backgrounds } \\
\hline Environmental engineers & $\begin{array}{l}\text { Typically engineers who have a deep understanding of } \\
\text { accounting rules, which is helpful for rate cases and in CBAs }\end{array}$ \\
\hline Safety specialists & $\begin{array}{l}\text { Expertise in ecology and environmental regulatory requirements, } \\
\text { which is helpful in transmission route planning and also in } \\
\text { managing environmental analysis subcontractors }\end{array}$ \\
\hline $\begin{array}{l}\text { Typically civil engineers who have a strong knowledge of } \\
\text { international standards and who can develop safety plans for } \\
\text { installation and operations and maintenance as well as equipment } \\
\text { security plans to protect assets from theft or vandalism }\end{array}$ \\
\hline $\begin{array}{l}\text { Valuable Soft Skill Sets } \\
\text { Contract oversight skills }\end{array}$ & $\begin{array}{l}\text { There are strict deadlines to provide comments on transmission } \\
\text { expansion proposals. }\end{array}$ \\
\hline $\begin{array}{l}\text { Public speaking ability, } \\
\text { composure during contentious } \\
\text { proceedings such as cross- } \\
\text { examinations, and negotiation } \\
\text { skills }\end{array}$ & $\begin{array}{l}\text { Environmental evaluations of proposed transmission routes are } \\
\text { often subcontracted to private firms. }\end{array}$ \\
\hline $\begin{array}{l}\text { Strong writing ability and } \\
\text { familiarity with the relevant legal } \\
\text { and regulatory framework }\end{array}$ & $\begin{array}{l}\text { A considerable amount of regulatory staff effort is dedicated to } \\
\text { participating in large stakeholder meetings such as public } \\
\text { hearings, rate cases, and technical subcommittees (e.g., those } \\
\text { managed by the system operator regulated by the commission } \\
\text { and cross-jurisdictional meetings). }\end{array}$ \\
\hline $\begin{array}{l}\text { Translation of complex grid } \\
\text { challenges into plain language }\end{array}$ & Staff is responsible for writing expert testimony. \\
\hline $\begin{array}{l}\text { Innovativeness and creative } \\
\text { thinking }\end{array}$ & $\begin{array}{l}\text { The commission will take on challenging issues such as the grid } \\
\text { integration of renewable energy. }\end{array}$ \\
\hline
\end{tabular}

Interviews with public utility commission staff from Texas and Colorado yielded several additional important insights on how the design of the regulatory system can significantly impact the personnel requirements of regulatory agencies. For example, both states include robust public participation in their transmission evaluation processes, which requires substantial personnel additions: lawyers, hearing officers, court recorders, administrators, and security personnel. Further, the defined role of the regulatory body in charge of evaluating transmission expansion projects can significantly impact the required skill sets. 
In California, the CPUC is responsible for complying with additional environmental requirements under the California Environmental Quality Act, a statute that requires state and local agencies to identify the significant environmental impacts of their actions. This compliance requires an increased emphasis on skill sets such as environmental engineers and individuals who have experience in ecology or biology.

\subsection{Regulatory Role}

Although CRE asked NREL to provide insight into the approval criteria for transmission investment recommendations by CENACE forthcoming in the PRODESEN, NREL acknowledges that CRE will be studying the broader possibilities for regulatory roles in the context of Mexico's Energy Transition Act and revising the regulatory framework. In the United States, FERC, NERC, and state regulatory commissions all play a role in overseeing transmission decisions. If CRE is tasked with taking on all of these independent regulator responsibilities in-house, it would need considerable time and investment to develop an appropriate structure of oversight and implement those processes.

For example, reliability standards span two categories: operations and planning. Because investments in transmission infrastructure and the anticipated PRODESEN are steps removed from these short-term equipment operations and utilization decisions, NREL did not focus on NERC's operational standards. Though the development, measurement, and enforcement of those standards is outside the scope of this work, NREL would be happy to provide detail and recommendations in a future document depending on how CRE's role evolves. NREL is also happy to discuss the possibility of CENACE adopting NERC standards or formally joining NERC as the mainland transmission operator. This is another area that was outside the scope of the work for this report.

Further, the cost allocation of transmission upgrades is not an area that was studied. It is assumed that PRODESEN's recommendations of investments are to be approved/disapproved by CRE and SENER, and that if they are approved they will be funded directly from the Mexican treasury. If there is a future open question of cost allocation between the Treasury and independent parties requesting transmission - for example, renewable energy developers - to better assist CRE in creating appropriate rules or provide background in this area for CRE to opine on any rules proposed, NREL would be happy to provide CRE with examples of cost allocation models that have worked in the United States and internationally. Transmission tariffs are an area generally regulated by FERC because transmission lines move power across state boundaries. For a good overview of regulation, please see the Regulatory Assistance Project (2011) or visit www.raponline.org.

\subsection{Stakeholder Process}

In continuation of the common theme of stakeholder engagement throughout transmission planning processes, CRE should consider formalizing that process in a tiered structure-for example, based on voltage class or magnitude of the monetary request. NREL would be happy to work with CRE to establish an appropriate protocol and recommend a planning group structure to coordinate the stakeholder engagement process. Examples of regional coordination groups in the United States include the Colorado Coordinated Planning Group and the Texas Regional Planning Group. 


\subsection{Value of Lost Load}

In response to comments from CRE, NREL will approach SENER with our capability to assist in the determining VOLL across Mexico's power sector. As discussed in Section 5.4, the work involves considering the type of customer affected, regional economic conditions and demographics, time and duration of outage, and other specific traits of an outage.

\subsection{Distribution System}

This report has focused on the transmission system. The distribution system reliability and regulation is important as well, but it was not possible to cover it within this scope. We think a future chapter on grid modernization will incorporate many innovative suggestions to leapfrog Mexico's power delivery sector to be a global example in the areas of smart grid deployment, smart substations, feeder-level sensing and measurement of power flow, device modeling, producer/consumer (prosumers), distributed generation, electric vehicles, demand response, energy storage, and communications. 


\section{Conclusion}

NREL encourages the continuation of dialogue with CRE on many of these issues. This project focused on transmission expansion project approval, and the scope of this report did not provide for the full depth that these topics warrant. Mexico is at an exciting crossroads in its history, and NREL can provide experience from the United States and international work we have done to facilitate the adoption of clean energy policies and regulations. We have provided some examples of regulatory processes in the United States, but we have not given specific recommendations to $\mathrm{CRE}$ on which aspects of various models would be appropriate for the energy transition in Mexico. We view this document as the first step in a process of assistance and not an end product to be put on a shelf. With the background provided here, we envision next steps as being far more dynamic and incorporating extensive dialogue with CRE and CENACE staff as well as custom-tailored solutions to ensure transmission and distribution system reliability. 


\section{References}

Ajodhia, V.S. 2006. Regulation Beyond Price: Integrated Price-Quality Regulation for

Electricity Distribution Networks. Delft, Netherlands: TU Delft, Delft University of Technology.

Bird, L., J. Cochran, and X. Wang. 2014. Wind and Solar Energy Curtailment: Experience and Practices in the United States (Technical Report NREL/TP-6A20-60983). Golden, CO: National Renewable Energy Laboratory.

CAISO. 2004. Transmission Economic Assessment Methodology (TEAM). Folsom, CA: June.

CAISO. 2012. "Draft Final Proposal: FERC Order 1000 Compliance Initiative.” Folsom, CA: July.

CAISO. 2013. Consideration of Alternatives to Transmission or Conventional Generation to Address Local Needs in the Transmission Planning Process. Folsom, CA: September.

CAISO. 2015a. 2014-2015 Conceptual Statewide Transmission Plan Update: California ISO 2015-2016 Regional Transmission Planning Process. Folsom, CA: August.

CAISO. 2015b. 2014-2015 Transmission Plan (version approved by CAISO Board of Directors). Folsom, CA: March 27.

CAISO. 2016. “California ISO.” Accessed January 6, 2016.

http://www.caiso.com/about/Pages/IndustryInsights/IndustryLinks/Utilities.aspx.

Chowdhury, A., and Le, D. 2009. "Application of California ISO Transmission Economic Assessment Methodology (TEAM) for the Sunrise Powerlink Project.” IEEE Power and Energy Society General Meeting: 1-5.

Colorado PUC. 2015. Code of Colorado Regulations: Rules Regulating Electric Utilities. Codes 3606, 3607, and 3627 refer to transmission and distribution planning. Accessed November 24, 2015. https://www.sos.state.co.us/CCR/GenerateRulePdf.do?ruleVersionId=5595.

Corbus, D., D. Hurlbut, P. Schwabe, E. Ibañez, G. Brinkman, A. Paduru, V. Diakov, and M. Hand. 2014. California-Wyoming Grid Integration Study: Phase 1-Economic Analysis (Technical Report NREL/TP-6A20-61192). Golden, CO: National Renewable Energy Laboratory, March.

CPUC. 2004a. "Project Need from Decision of the Application of Pacific Gas and Electric Company for a Certificate of Public Convenience and Necessity Authorizing the Construction of the Jefferson-Martin $2030 \mathrm{kV}$ Transmission Project." CPUC Decision, August 2004. Accessed December 11, 2015. http://docs.cpuc.ca.gov/published//FINAL_DECISION/3912203.htm\#P194_39782. 
CPUC. 2004b. "Decision of the Application of Pacific Gas and Electric Company for a Certificate of Public Convenience and Necessity Authorizing the Construction of the JeffersonMartin 2030 kV Transmission Project." CPUC Decision, August 2004. Accessed December 11, 2015. http://docs.cpuc.ca.gov/published//FINAL_DECISION/39122.htm.

CPUC. 2009. Overview of Electric Transmission Siting at the California Public Utilities Commission. San Francisco, CA.

CPUC. 2015a. California Public Utilities Code: Section 1001-1013. Accessed November 24. 2015. http://www.leginfo.ca.gov/cgi-bin/displaycode? section=puc\&group $=01001$ $\underline{02000 \& \text { file }=1001-1013}$.

CPUC. 2015b. “Transmission and Environmental Permitting.” Accessed November 24, 2015. http://www.cpuc.ca.gov/PUC/energy/Environment/.

CPUC. 2016. "CPUC Long Term Procurement Plan.” Accessed January 14, 2016. http://www.cpuc.ca.gov/General.aspx?id=4789.

Ela, E., V. Gevorgian, P. Fleming, Y.C. Zhang, M. Singh, E. Muljadi, A. Scholbrook, J. Aho, A. Buckspan, L. Pao, V. Singhvi, A. Tuohy, P. Pourbeik, D. Brooks, and N. Bhatt. 2014a. Active Power Control from Wind Power: Bridging the Gaps (Technical Report NREL/TP-5D0060574). Golden, CO: National Renewable Energy Laboratory.

Ela, E., M. Milligan, A. Bloom, A. Botterud, A. Townsend, and T. Levin. 2014b. Evolution of Wholesale Electricity Market Design with Increasing Levels of Renewable Generation (Technical Report NREL/TP-5D00-61765). Golden, CO: National Renewable Energy Laboratory.

ERCOT. 2008. "Competitive Renewable Energy Zone (CREZ) Transmission Optimization Study. System Planning Report submitted to the Public Utility Commission of Texas in Docket No. 33672, Commission Staff's Petition for Designation of Competitive Renewable Energy Zones."

ETT. 2015. "Electric Transmission Texas: Projects \& Project Plans: The Laredo VFT Project." Accessed December 1, 2015. http://www.ettexas.com/projects/vft.asp.

FERC. 2010a. Notice of Proposed Rulemaking: Order No. 1000-Transmission Planning and Cost Allocation, accessed January 13, 2016. http://www.ferc.gov/industries/electric/indusact/trans-plan.asp.

FERC. 2010b. Order Accepting Tariff Revisions (Docket No. ER10-1069-000). June 17, 2010.

FERC. 2011. Order No. 1000-Transmission Planning and Cost Allocation by Transmission Owning and Operating Public Utilities. https://www.ferc.gov/whats-new/commmeet/2011/072111/E-6.pdf. 
FERC. 2015. ISO New England Docket No. ER15-1509-000, and New England Power Pool Participants Committee Docket No. ER15-1509-001. July 23, 2015. Accessed January 7, 2016. http://www.iso-ne.com/static-assets/documents/2015/07/er15-1509-000 and er15-1509-001.pdf.

FERC. 2016. "Electric Power Markets-Texas." Accessed January 14, 2016.http://www.ferc.gov/market-oversight/mkt-electric/texas.asp.

Gevorgian, V., and B. O'Neill. 2016. Advanced Grid-Friendly Controls Demonstration Project for Utility-Scale PV Power Plants Project (Technical Report NREL/TP-5D00-65368). Golden, CO: National Renewable Energy Laboratory.

Ibanez, E., and M. Milligan. 2014. "Comparing Resource Adequacy Metrics and their Influence on Capacity Value" (presented at the $13^{\text {th }}$ International Conference on Probabilistic Methods Applied to Power Systems, Durham, United Kingdom, July 7-10, 2014).

Johnson, R. 2015. Grid integration in the West: Bulk Electric System Reliability, Renewable Energy Integration, \& Economic Efficiency. Menlo Park, CA: The Hewlett Foundation and the Energy Foundation, July.

LaCommare, K.H., and J.H. Eto. 2006. "Cost of Power Interruptions to Electricity Consumers in the United States (US).” Energy 31:12 (Sept.): 1845-1855.

Leahy, E., and R.S.J. Tol. 2011. "An Estimate of the Value of Lost Load for Ireland." Energy Policy 39(3) Mar.: 1514-1520.

London Economics. 2013. Estimating the Value of Lost Load: Briefing Paper Prepared for the Electric Reliability Council of Texas, Inc., by London Economics International, LLC. Austin, TX: Electric Reliability Council of Texas.

Mickey, J. 2014. "ERCOT Presentation on US-Mexico Cross-Border Trade" (presented at the NARUC Summer Meeting, Dallas, Texas, July 2014).

Miller, N.W., M. Shao, S. Pajic, and R. D'Aquila. 2014. Western Wind and Solar Integration Study Phase 3-Frequency Response and Transient Stability (Technical Report NREL/SR5D00-62906). Golden, CO: National Renewable Energy Laboratory.

Miller, N.W., B. Leonardi, R. D'Aquila, and K. Clark. 2015. Western Wind and Solar Integration Study Phase 3A: Low Levels of Synchronous Generation (Technical Report NREL/TP-5D00-64822). Golden, CO: National Renewable Energy Laboratory.

Milligan, M. 2011. "Methods to Model and Calculate Capacity Contributions of Variable Generation for Resource Adequacy Planning (IVGTF1-2)" (presented to the Joint NERC-UVIG Workshop, Kansas City, MO, April 12, 2011).

Milligan, M., E. Zhou, B. Frew, and D. Arent. 2015. Advancing System Flexibility for High Penetration Renewable Integration (Technical Report NREL/TP-5D00-64864). Golden, CO: National Renewable Energy Laboratory. 
National Association of Clean Air Agencies. 2015. "Implementing EPA's Clean Power Plan: A Menu of Options."

NERC. 2013. "Informational Filing on the Definition of "Adequate Level of Reliability." May 10, 2013. Accessed January 7, 2015.

http://www.nerc.com/FilingsOrders/us/NERC\%20Filings\%20to\%20FERC\%20DL/Informational _Filing_Definition_Adequate_Level_Reliability_20130510.pdf.

NERC. 2015a. “About NERC.” Accessed December 1, 2015.

http://www.nerc.com/AboutNERC/Pages/default.aspx.

NERC. 2015b. “Adequate Level of Reliability.” Accessed January 7, 2015.

http://www.nerc.com/files/Adequate_Level_of_Reliability.pdf.

NERC. 2015c. "Standards." Accessed December 1, 2015.

http://www.nerc.com/pa/Stand/Pages/default.aspx.

Pfeifenberger, J., J. Chang, and A. Sheilendranath. 2015. Toward More Effective Transmission Planning: Addressing the Costs and Risks of an Insufficiently Flexible Electricity Grid.

Cambridge, MA: The Brattle Group, April.

Praktiknjo, A.J., A. Hähnel, and G. Erdmann. 2011. “Assessing Energy Supply Security: Outage Costs in Private Households.” Energy Policy 39(12) Dec.: 7,825-7,833.

PUCT. 2003. Filing Documents Case 28834-2: Application of Sharyland Utilities for a Certificate of Convenience and Necessity $(\mathrm{CCN})$ for a 138-kV Transmission Line in Hidalgo County, Texas, to Implement a High-Voltage Direct Current Interconnection with Comision Federal de Electricidad. Accessed December 1, 2015, http://interchange.puc.texas.gov/WebApp/Interchange/application/dbapps/filings/pgSearch_Resu lts.asp?TXT_CNTR_NO=28834\&TXT_ITEM_NO=2.

PUCT. 2005. Filing Documents Case 28834-117: Final Order-Application of Sharyland Utilities for a Certificate of Convenience and Necessity (CCN) for a 138-kV Transmission Line in Hidalgo County, Texas, to Implement a High-Voltage Direct Current Interconnection with Comision Federal de Electricidad. Accessed December 1, 2015, http://interchange.puc.texas.gov/WebApp/Interchange/application/dbapps/filings/pgSearch_Resu lts.asp?TXT_CNTR_NO=28834\&TXT_ITEM_NO=117.

PUCT. 2011. "Landowners and Transmission Line Cases at the PUCT."

PUCT. 2015. "Electric Substantive Rules: Chapter 25 Rules Applicable to Electric Service Providers-Subchapter E. Certification, Licensing and Registration.” Accessed November 23, 2015. http://www.puc.texas.gov/agency/rulesnlaws/subrules/electric/Electric.aspx.

PURA. 1997. Utilities Code: Chapter 37. Certificates of Convenience and Necessity, 1997. Accessed November 23, 2015. http://www.statutes.legis.state.tx.us/Docs/UT/htm/UT.37.htm . 
Regulatory Assistance Project. 2011. Electricity Regulation in the US: A Guide. Montpelier, VT.

SENER ("Secretaría de Energía”). 2015. Accessed December 1, 2015, http://www.energia.gob.mx/.

Transmission and Environmental Permitting Team of CPUC. 2009. "General Information on Permitting Electric Transmission Projects at the California Public Utilities Commission (CPUC)" (Presentation). San Francisco, CA: June.

Tri-State Generation and Transmission Association, Inc. 2010. "Application for a CPCN for the San Luis Valley-Calumet-Comanche Transmission Project in the State of Colorado." Accessed December 1, 2015. http://www.dora.state.co.us/puc/DocketsDecisions/DocketFilings/09A324E_-325E/09A-324E_-325E_Tri-State02-25-10SOP.pdf.

Vansant, C. 2012. “FERC Rule 1000: What Does It Mean?” POWER Magazine July 1.

Welle, A.V.D., and B.V.D. Zwaan. 2007. An Overview of Selected Studies on the Value of Lost Load (VOLL). Amsterdam, Netherlands: Energy Research Centre of the Netherlands.

Western Governors' Association and U.S. Department of Energy. 2009. Western Renewable Energy Zones-Phase 1 Report. Washington, D.C.: June.

Winsor, G., and S. Buncombe. 2007. "Repair/Replace Decision Making Practices" (presented at the ICOMS Asset Management Conference, Melbourne, Australia, May 21-24, 2007). 